\title{
Thermomechanical Stresses Drive Damage of Alpine Valley Rock Walls During Repeat Glacial Cycles
}

\section{Journal Article}

Author(s):

Grämiger, Lorenz M.; Moore, Jeffrey R.; Gischig, Valentin; Loew, Simon (1)

Publication date:

2018-10

Permanent link:

https://doi.org/10.3929/ethz-b-000301116

Rights / license:

In Copyright - Non-Commercial Use Permitted

Originally published in:

Journal of Geophysical Research: Earth Surface 123(10), https://doi.org/10.1029/2018JF004626

Funding acknowledgement:

135184 - Paraglacial Rock Slope Mechanics (SNF)

146593 - Paraglacial Rock Slope Mechanics (Phase II) (SNF) 


\section{Journal of Geophysical Research: Earth Surface}

\section{RESEARCH ARTICLE}

10.1029/2018JF004626

Key Points:

- Subsurface temperature changes on glacial time scales can generate rock mass damage through

thermomechanical coupled stresses

- Glacier advances are most effective in producing rock slope damage as cooling drives contraction of subglacial bedrock

- Thermal shock during deglaciation creates a shallow damage front as bedrock is first exposed to annual temperature cycles

Supporting Information:

- Supporting Information S1

- Data Set S1

Correspondence to:

L. M. Grämiger,

graemiger.lorenz@gmail.com

\section{Citation:}

Grämiger, L. M., Moore, J. R., Gischig, V. S., \& Loew, S. (2018).

Thermomechanical stresses drive damage of Alpine valley rock walls during repeat glacial cycles. Journal of Geophysical Research: Earth Surface, 123 https://doi.org/10.1029/2018JF004626

Received 6 FEB 2018 Accepted 24 SEP 2018 Accepted article online 27 SEP 2018

\section{Thermomechanical Stresses Drive Damage of Alpine Valley Rock Walls During Repeat Glacial Cycles}

\author{
Lorenz M. Grämiger' ${ }^{1}$, Jeffrey R. Moore ${ }^{1,2}$ iD, Valentin S. Gischig ${ }^{1}$ D, and Simon Loew ${ }^{1}$ iD \\ ${ }^{1}$ Department of Earth Sciences, ETH, Zurich, Switzerland, ${ }^{2}$ Department of Geology and Geophysics, University of Utah, Salt \\ Lake City, UT, USA
}

Abstract Cycles of glaciation alter the temperature field in proximal alpine valley flanks, driving rock slope damage through thermomechanical stresses. Here we extend simplified assumptions of glacial debuttressing to quantitatively examine how paraglacial bedrock temperature changes, acting in concert with changing ice loads during Late Pleistocene and Holocene glacial cycles, create damage in adjacent rock slopes and prepare future slope instabilities. When in contact with temperate glacier ice, valley walls maintain near isothermal $\sim 0{ }^{\circ} \mathrm{C}$ surface temperatures and are shielded from daily and annual cycles. With retreat, rock walls are rapidly exposed to strongly varying temperature boundary conditions, a transition we term "paraglacial thermal shock." Using detailed, conceptual numerical models based on the Aletsch Glacier in Switzerland, we show that including thermomechanical stresses during simulated glacial cycles creates significantly more rock slope damage than predicted for purely mechanical ice loading and unloading. Glacier advances are especially effective in generating damage as rapid cooling drives contraction of the rock mass reducing joint normal stresses. First time exposure to annual temperature cycles during deglaciation induces a shallow damage front that follows the retreating ice margin, generating damage in a complementary process at shorter time scales. Acting on a reduced strength rock mass, modeled thermomechanical cycles enhance the development of a slope instability with similar attributes as observed in our study area. Our results demonstrate that thermomechanical stresses acting in conjunction with changing ice loads are capable of generating considerable rock slope damage with spatial and temporal patterns controlled by glacier extents.

\section{Introduction}

Rock slope failures are frequently located in the vicinity of retreating glaciers, shaping alpine landscapes and representing a hazard to mountain communities and infrastructure (e.g., Ballantyne, 2002; Evans \& Clague, 1994; Kos et al., 2016; McColl, 2012). Slope instabilities result from the accumulation of rock mass damage over time (i.e., creation of new fractures, propagation of slip along existing joints, and failure of intact rock bridges), which may occur in conjunction with or independent from an ultimate failure trigger (Figure 1a; Terzaghi, 1962; Eberhardt et al., 2004; Gunzburger et al., 2005; Gischig et al., 2015). Slope debuttressing associated with glacier retreat (i.e., removal of an ice buttress) is often suggested to be a principal mechanism driving damage in glacially oversteepened rock walls, preparing or triggering postglacial alpine slope failures (e.g., Bovis, 1990; Cossart et al., 2008; Jaboyedoff et al., 2012). However, because ice behaves in a ductile manner at long time scales ( $>$ tens of years) and small strain rates $\left(<10^{-3} \mathrm{~s}^{-1}\right.$; Schulson, 1990), glaciers make a poor buttress for ice-marginal slopes (Grämiger et al., 2017; McColl et al., 2010; McColl \& Davies, 2013), loading underlying bedrock by their weight alone and not providing rigid lateral support to adjacent valley walls. Simplified or incomplete views of glacial debuttressing thus hinder attempts to better understand the evolution of paraglacial rock slope instabilities and their respective hazards, as illustrated by frequently observed large lag-times between deglaciation and the timing of slope failure (e.g., Ballantyne et al., 2014a; Ballantyne \& Stone, 2013), motivating detailed studies into the mechanics of time-dependent paraglacial rock mass damage.

Deglaciation causes more than a simple reduction in the weight of ice at the toe a proximal rock slope. Glaciers occupying an alpine valley exert strong control on subsurface temperatures and hydrology (Boulton et al., 2004; McColl et al., 2010; Wegmann et al., 1998), and glacier retreat imposes changes in these primary fields that can drive rock mass damage through coupled mechanical stresses. Notably, glacier advance and retreat create a transient disturbance in the local temperature field on both short (daily and annual) and long (decadal to millennial) time scales. Bedrock in contact with temperate glacial ice will 

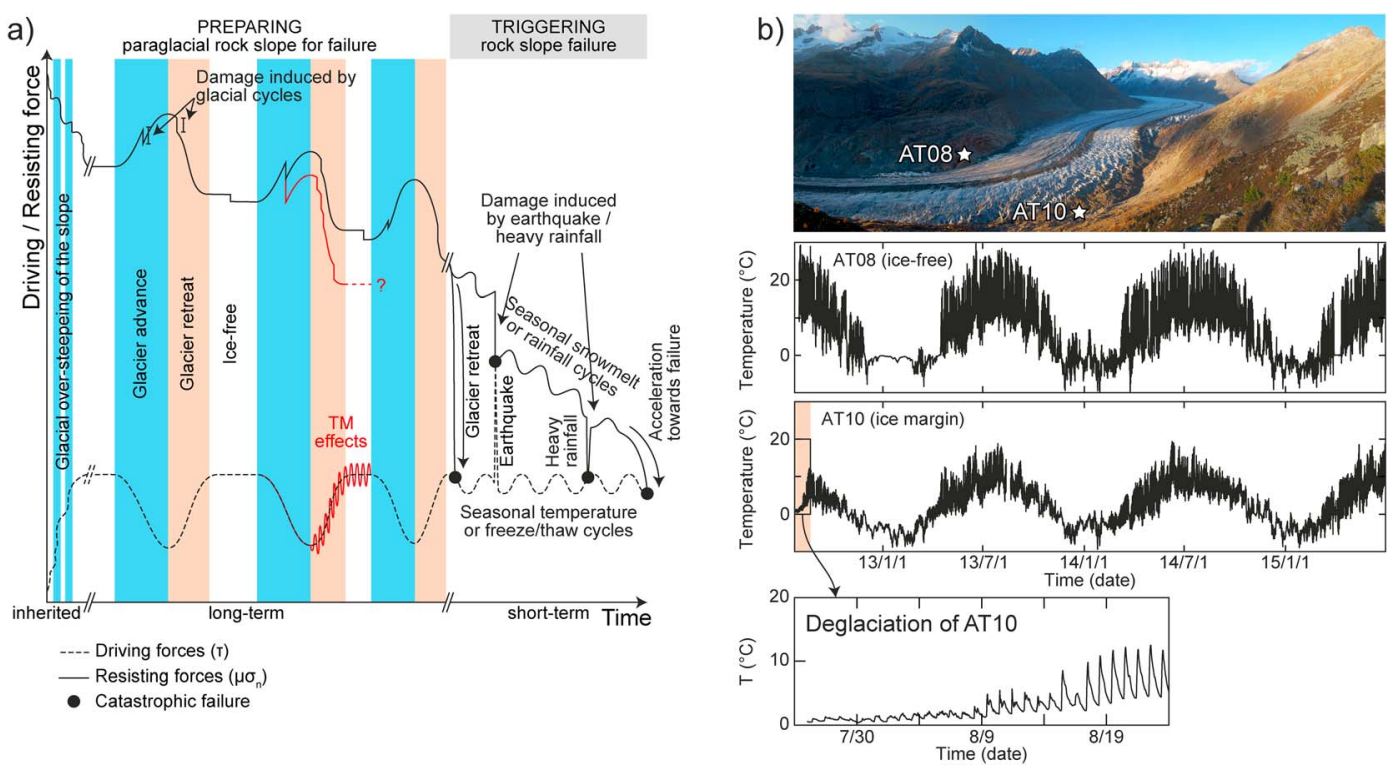

Figure 1. Concept of paraglacial rock slope preparation until ultimate failure: (a) variation of driving and resisting forces in a rock slope during repeat glacial cycles. Incremental damage induced by glacier advance and retreat as purely mechanical loading and unloading (Grämiger et al., 2017) together with other preparatory factors during ice-free conditions reduces slope stability until a critical state is reached. A single small disturbance may become the ultimate trigger for catastrophic failure (adapted from Gunzburger et al., 2005 and Gischig et al., 2015). Glacier cycles together with other fatigue mechanisms, for example, TM effects, may show greater potential in slope preparation (red line). (b) The paraglacial environment of the Great Aletsch Glacier in our study area. The asterisks mark the position of ground temperature measurements: AT08 showing ice-free temperature conditions with daily and annual cycles near the glacier, and AT10 showing the temperature signal of rock suddenly exposed to new temperature conditions by deglaciation.

maintain relatively constant temperatures near the pressure melting point (approximately $0{ }^{\circ} \mathrm{C}$ ) and is shielded from solar radiation and ambient air temperature changes (Wegmann et al., 1998). In contrast, bedrock uncovered from beneath retreating ice is rapidly exposed to drastically different thermal boundary conditions, with daily and annual temperature fluctuations superposed on a new mean temperature, a transition we term paraglacial thermal shock and demonstrate with temperature data from our study area in Figure 1b. Thermomechanical (TM) stresses resulting from these temperature changes are not only strongest in the near-surface but also extend below the thermally active layer (the area subject to annual temperature changes) and can drive progressive failure at depths of $100 \mathrm{~m}$ or more (Gischig et al., 2011a, 2011b). Therefore, as ice retreats and exposes bedrock along marginal valley walls, a rapidly forming shallow TM damage front should follow closely along the ice-rock contact. Meanwhile, the diffusive thermal front at greater depths lags surface temperature changes and can drive delayed rock mass damage as the geothermal gradient adjusts to the new mean annual ground-surface temperature (MAGT). The resulting zone affected by TM stresses may coincide with the area of critically stressed bedrock created by mechanical ice unloading (Grämiger et al., 2017), increasing the degree of rock mass damage associated with glacial cycles.

Thermal effects such as frost cracking (Duca et al., 2015; Hales \& Roering, 2007; Sanders et al., 2012; Wegmann \& Gudmundsson, 1999) or permafrost degradation (Draebing et al., 2014; Hasler et al., 2012; Krautblatter et al., 2013) have been widely recognized as important physical weathering processes shaping bedrock landscapes. However, damage created by thermoelastic strain in rock masses is frequently dismissed and has only recently been investigated in more detail (Bakun-Mazor et al., 2013; Collins \& Stock, 2016; Eppes et al., 2016; Gischig et al., 2011a, 2011b; Gunzburger et al., 2005; Hall, 1999; Hall \& André, 2001; Watson et al., 2004). Baroni et al. (2014) highlighted the importance of considering long-term TM effects during deglaciation of an alpine valley, although the resulting displacement rates from their numerical simulations were too low to explain the development of slope instabilities. Gischig et al. (2011a) demonstrated how seasonal temperature changes can drive deep rock slope deformation and damage and highlighted an initial $\sim 5$-year thermaltransient phase of considerable TM damage as the rock mass first adapts to new thermal boundary conditions. Other studies reveal the impact of glacier retreat on permafrost penetration in rock walls at high altitudes, which may enhance frost cracking (Wegmann et al., 1998; Wegmann \& Gudmundsson, 1999), but 
did not analyze damage caused by thermal strain in fractured rock masses. In a paraglacial environment (Slaymaker, 2009), where rock slopes are adjusting to the change from glacial to nonglacial conditions (Figure 1a), several other processes also act in conjunction with glacier advance and retreat, include chemical weathering (Jaboyedoff et al., 2004), stress corrosion (Faillettaz et al., 2010), changes in joint water pressure (Hansmann et al., 2012; Preisig et al., 2016), or seismic fatigue (Gischig et al., 2015; McColl et al., 2012). Each of these processes is affected by the current and past position of the proximal valley glacier, which controls the location and magnitude of local rock slope damage. Glacier advances generally increase joint normal stresses and decrease shear stresses; that is, driving forces are reduced and resisting forces enhanced, while the reverse is encountered during retreat. Accumulation of incremental damage with each glacial cycle prepares the slope for failure, reducing slope stability over time until a final trigger leads to catastrophic failure (Eberhardt et al., 2004; Gischig et al., 2015; Prager et al., 2008).

In this study, we expand on earlier investigations by Grämiger et al. (2017), which addressed the purely mechanical impact of glacier cycles on paraglacial rock slope damage, to include temperature changes and resulting thermal strain induced by glacial advance and retreat, moving beyond simplified views of glacial debuttressing by incorporating coupled mechanical processes. We introduce TM coupling in the distinctelement numerical modeling framework first described by Grämiger et al. (2017), which is based on detailed assessment and field characterization of our Aletsch Valley study site in Switzerland. Our results show how long-term temperature changes and annual cycles interact with changing ice loads to drive TM rock mass damage. We compare predictions of TM damage with our previous results of purely mechanical ice loading and unloading and describe in detail how TM effects acting in combination with glacier cycles lead to failure of intact rock bridges, propagate fractures, and enhance slip along discontinuities. Our results thus expand the understanding of processes facilitating the development of paraglacial rock slope instabilities.

\section{Paraglacial Setting of the Aletsch Region}

\subsection{Study Site and Rock Slope Instabilities}

Our study area comprises rock slopes surrounding the Great Aletsch Glacier in the central Swiss Alps (Figure 2). Bedrock consists of gneisses of the metamorphic Altkristallin and Central Aare granites in the Aar Massif (Steck, 2011). Steep to subvertical foliation dipping SE (dip/dip direction: $76^{\circ} / 122^{\circ}$ ) and faults following the alpine foliation are the dominant geological structures (Grämiger et al., 2017). An additional steep joint set perpendicular to foliation $\left(83^{\circ} / 198^{\circ}\right)$ and a joint set dipping gently SW $\left(20^{\circ} / 240^{\circ}\right)$ are also present in the generally blocky rock mass (GSI 65-80).

Valley flanks in the vicinity of the Great Aletsch Glacier host several rock slope instabilities with different dimensions and kinematics (Figure 2), described in detail by Grämiger et al. (2017). We mapped a concentration of landslides around the present-day glacier terminus, some of which have been investigated in detail (e.g., Kääb, 2002; Kos et al., 2016; Loew et al., 2017; Strozzi et al., 2010). Landslides on the eastern valley flank are characterized by toppling kinematics, while the western slope contains compound rock slides. To the south, a large deep-seated gravitational slope deformation affects the slope around Belalp. Another very large deep-seated gravitational slope deformation along the western flank of the Rhone Valley, extending from Riederalp to Fiescheralp, is not directly affected by the Great Aletsch Glacier and is not analyzed in this study.

\subsection{Late Glacial and Holocene Glaciation}

The Pleistocene epoch was characterized by repeat major glacial/interglacial cycles in the European Alps. The extents of the Great Aletsch Glacier changed by several kilometers during the Late Glacial and Holocene (Figures 2 and 3). Likely warmer and ice-free conditions prevailed during the penultimate Eemian interglacial period ( 130 to $\sim 115 \mathrm{kyr}$; Dahl-Jensen et al., 2013). The following glacial period (Würmian) lasted $\sim 100 \mathrm{kyr}$ and peaked at the Last Glacial Maximum (LGM), dated at 28 to 18 kyr (Ivy-Ochs, 2015; Ivy-Ochs et al., 2008; Figure 3). Trimlines in our study area provide evidence of ice elevations at that time (Figure 2). Strong retreat of the LGM glacier system occurred by 19 to 18 kyr (Ivy-Ochs, 2015; Wirsig et al., 2016), followed by a series of successive Late Glacial readvances (Gschnitz, Clavadel, Daun, and Egesen stadia; Darnault et al., 2012; IvyOchs et al., 2008; Maisch et al., 1999). Moraines of the Egesen stadial are well preserved at Aletsch, and cosmogenic exposure ages (Kelly et al., 2004; Schindelwig et al., 2012) coincide with the Younger Dryas (YD) cold period (12.8-11.5 kyr B.P.; Alley et al., 1993). Following the YD, the Great Aletsch Glacier retreated significantly. 


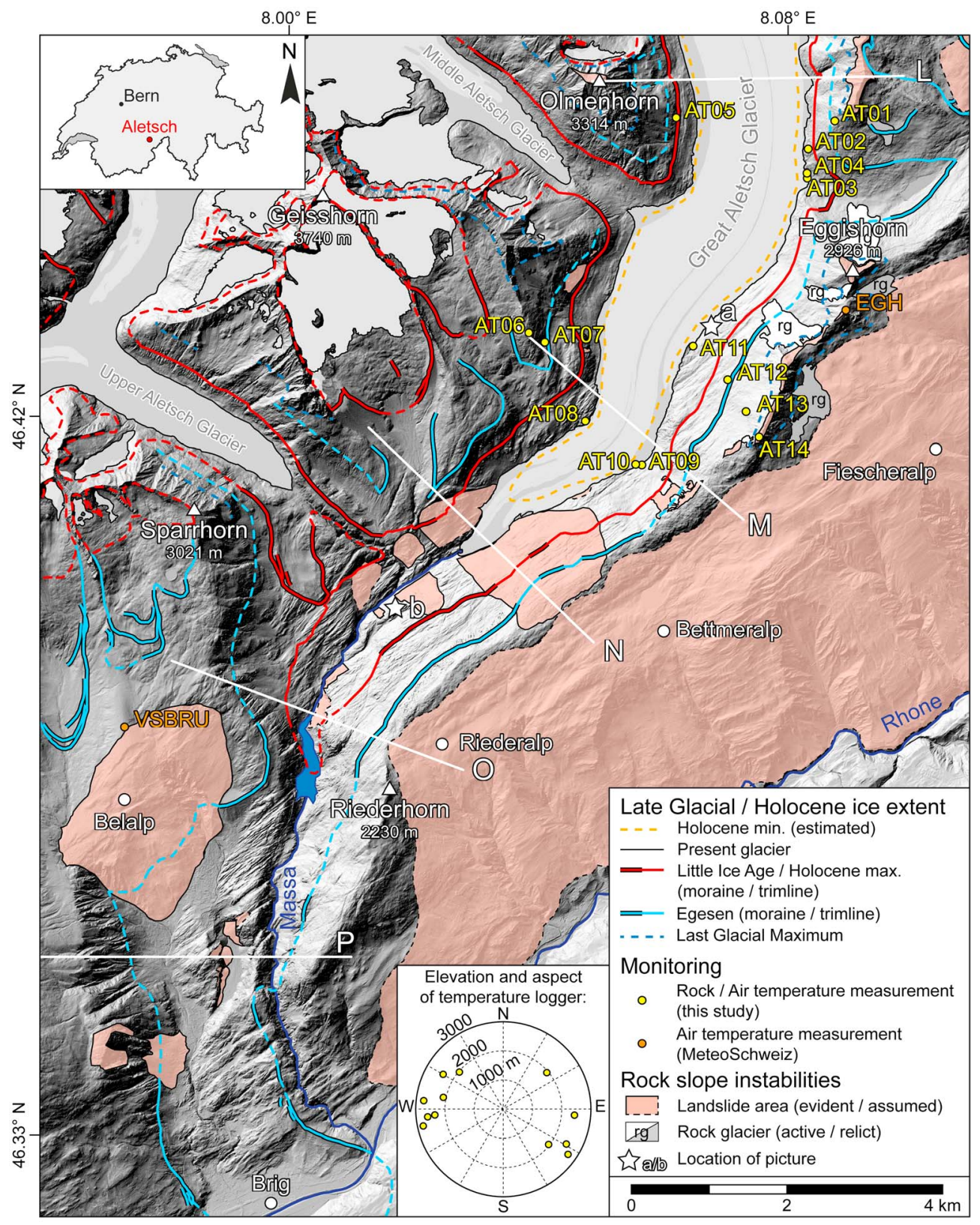

Figure 2. Synopsis of Late Glacial and Holocene glacier extents combined with spatial landslide extents mapped in the Aletsch region (modified from Grämiger et al., 2017): Hillshade derived from DTM (swissALTI3D by Swisstopo). Positions of rock and air temperature measurements (this study) and air temperature measurements from nearby weather stations (MeteoSchweiz) are shown. Inset: elevation and aspect of temperature sensors.

Extrapolating from other glaciers in the Alps, the Great Aletsch Glacier was likely smaller than at present during most of the Holocene but experienced several readvances culminating in the Little Ice Age (LIA) around the year 1850 (Figure 3; Ivy-Ochs et al., 2009; Joerin et al., 2006; Nicolussi \& Schlüchter, 2012; Röthlisberger \& Schneebeli, 1979; Schimmelpfennig et al., 2012). Reconstruction of ice extents at the Great Aletsch Glacier during the past $\sim 3,500$ years reveals more than three advance/retreat cycles, each reaching the Holocene glacial maximum (Holzhauser et al., 2005). The extent of the LIA is clearly visible (Figure 2). Minimum glacier extents, however, are difficult to verify. Holzhauser et al. (2005) postulated that during the mid-Holocene, the Great Aletsch Glacier was at least $\sim 1 \mathrm{~km}$ shorter than today (see Figures 2 and 3). 


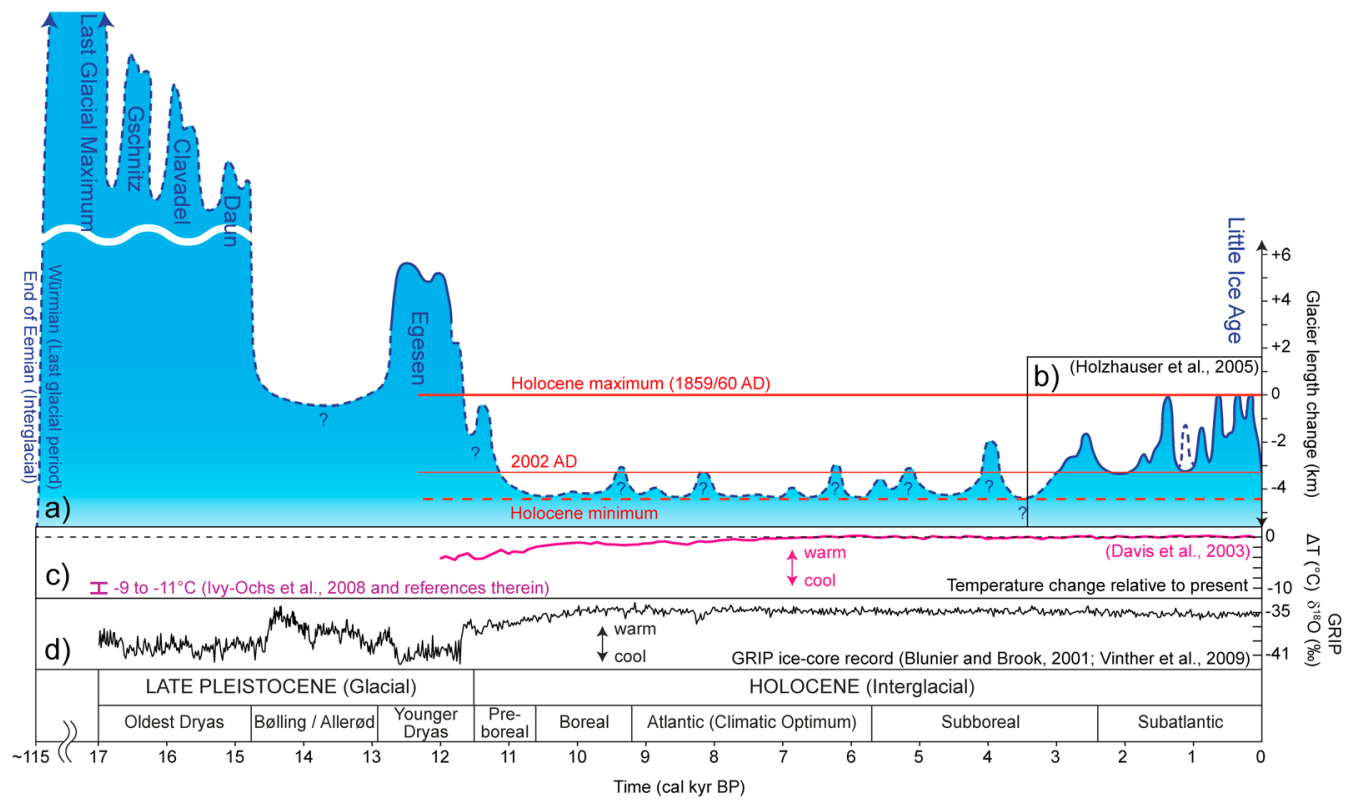

Figure 3. Synopsis of fluctuations of the Great Aletsch Glacier during the Late Glacial and Holocene (modified from Grämiger et al., 2017): (a) estimated length of the Great Aletsch Glacier with respect to the Little Ice Age extent compiling available information since the onset of the last glacial period until present (Grämiger et al., 2017, and references therein). (b) Detailed length reconstruction of the Great Aletsch Glacier from fossil tree trunks (Holzhauser et al., 2005). (c) Holocene temperature reconstruction from pollen data (Davis et al., 2003) and estimates of Late Glacial temperature change (Ivy-Ochs et al., 2008) relative to present. (d) Oxygen isotope record from the Greenland Ice Core Project illustrating climatic fluctuations (Blunier \& Brook, 2001; Vinther et al., 2009).

\subsection{Present and Late Glacial Temperature Regime}

Elevations in our study area span more than 3,000 $\mathrm{m}$ from high-alpine summits exceeding 4,000 $\mathrm{m}$ to the Rhone Valley at Brig $(691 \mathrm{~m})$. We collected continuous in situ rock temperature data over more than 3 years along valley profiles (Figure 2 ) in order to estimate present spatial and temporal ground temperature variations in the region. We also measured the temperature transition in bedrock experiencing glacier retreat (Figure 1b). A detailed description and discussion of our ground temperature measurements is presented in Appendix A1. From analysis of these data, we approximate ground-surface temperature $(T)$ as a function of time $(t)$ and elevation $(z)$ as

$$
T(t, z)=15.3-0.005(z)+10 \sin (2 \pi \mathrm{ft})
$$

where $t$ is time in seconds, $z$ is elevation in meters, and $f$ is the 1-year annual frequency in $\mathrm{Hz}$. This approximation leads to a $0{ }^{\circ} \mathrm{C}$ isotherm for the MAGT at 3,060 $\mathrm{m}$ above sea level.

Air temperatures varied strongly between glacial and interglacial periods. Different geological archives provide insights into paleotemperatures (Heiri et al., 2014). Oxygen isotope records from the Greenland Ice Core Project (Blunier \& Brook, 2001; Vinther et al., 2009) provide continuous information about the prevailing temperature regime during the last glacial and interglacial periods (Figure 3d). Davis et al. (2003) reconstructed Holocene temperature changes from pollen data in central Europe (Figure 3c). During the Gschnitz stadial (17-16 kyr), summer temperatures were likely $9-11^{\circ} \mathrm{C}$ colder than today (Ivy-Ochs et al., 2008, and references therein). Temperatures generally increased toward the onset of the Holocene. Estimated summer temperatures during the YD were $3.5^{\circ} \mathrm{C}$ colder than today (Ivy-Ochs et al., 2008), while in the early Holocene ( $\sim 8 \mathrm{kyr}$ ) temperatures had risen to within $1{ }^{\circ} \mathrm{C}$ of present conditions (Davis et al., 2003). Temperatures were slightly warmer than today during the Holocene Climatic Optimum, but in general during the Holocene temperatures likely varied by only about $\pm 1{ }^{\circ} \mathrm{C}$ (Davis et al., 2003).

Following LGM deglaciation, rock slopes above and outside the LIA extents most likely experienced only a single glacier readvance during the YD, while rock walls within and below the LIA extent were affected by 


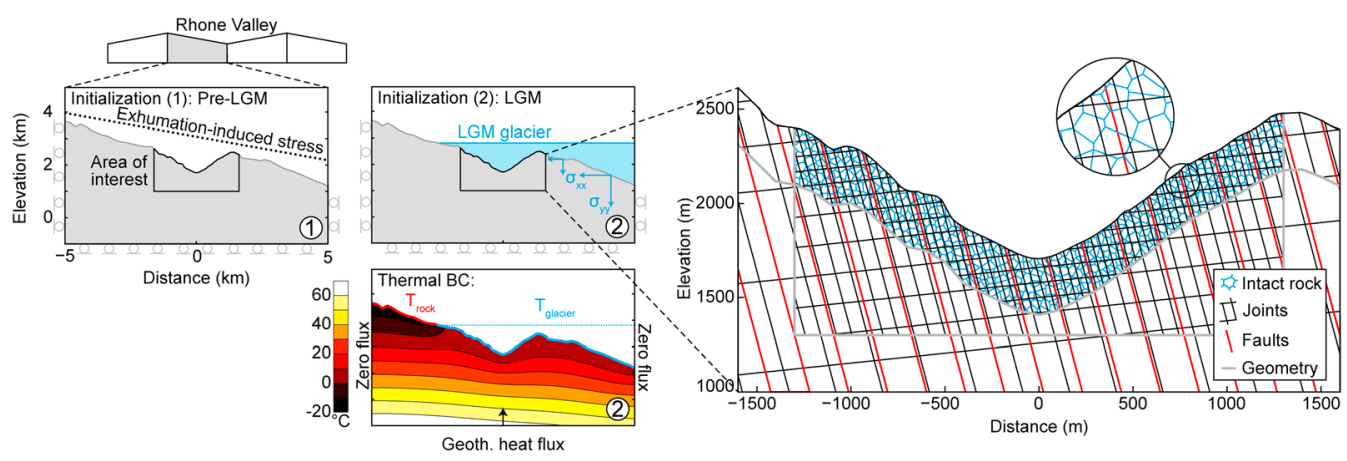

Figure 4. Initialization procedure, initial temperature field for long-term models with thermal boundary conditions in COMSOL, and model geometry (cross-section M) in UDEC: large-scale model with roller boundary conditions representing the western slope of the Rhone Valley undergoing two-stage initialization (pre-LGM/LGM). Embedded area of interest contains three rock mass elements: intact rock (Voronoi contacts), discontinuities (joints), and fault zones.

several glacier cycles. Each ice advance and retreat phase altered the thermal boundary conditions in adjacent valley walls. For simplicity, we assume bedrock in contact with temperate glacier ice maintains a constant $0{ }^{\circ} \mathrm{C}$ surface temperature, despite small expected variations of the pressure melting point of ice with depth and impurities (Harrison, 1975), while rock outside the ice limits has MAGT controlled by time and elevation with superposed annual cycles. Bedrock in the upper Aletsch Valley may have remained covered by ice and not experienced seasonal thermal cycles since the last interglacial roughly $\sim 110 \mathrm{kyr}$ ago. Future climate warming and glacier retreat (Jouvet et al., 2011) will expose this bedrock to drastically different thermal conditions.

\section{Numerical Study of TM Rock Slope Damage and Displacement}

\subsection{Model Approach and Inputs}

We expand the purely mechanical numerical modeling framework introduced by Grämiger et al. (2017) to include TM effects associated with glacial cycles. Our approach uses the 2-D distinct-element code UDEC (Cundall \& Hart, 1992; Itasca, 2014), which is well suited for analyzing the behavior of a discontinuous rock mass. We calculated transient temperature fields using the finite element code COMSOL Multiphysics (2015), which were then provided as input data for UDEC. Thermal gradients were calculated in COMSOL for each mechanical step and were passed on to compute the mechanical response in UDEC, which was run to a mechanical equilibrium (quasi steady state) that also considers thermal strain. In this semicoupled approach, temperature gradients induce mechanical strain, but the resulting mechanical response does not influence the thermal boundaries, properties, or temperature field.

Figure 4 shows our model geometry and TM initialization steps. The model cross section represents profile $M$ (see Figure 2). Model geometry, discontinuities, and rock properties are based on field mapping and rock mass characterization described in detail by Grämiger et al. (2017). The area of interest is embedded into a large-scale model of the Rhone Valley and contains three rock mass elements: (1) intact rock, (2) discontinuities (joints), and (3) brittle-ductile fault zones (Figure 4). Randomly oriented discontinuities (i.e., Voronoi polygons; Lorig \& Cundall, 1989) represent intact rock and allow for the formation of new, unascribed failure pathways. The orientation, spacing, persistence, and strength parameters for each rock mass constituent are based on field assessment. Blocks between discontinuities are assigned elastic properties (Table 1), while discontinuities (i.e., joints, faults, and Voronoi contacts) are assigned a Mohr-Coulomb constitutive law including slip-weakening of friction, cohesion, and tensile strength (Table 2 and Appendix A2). In contrast to other formulations of slip-weakening in literature, where weakening occurs over a finite slip distance, slip-weakening in UDEC occurs instantaneously; that is, once peak strength is exceeded, strength falls to residual values instantaneously, and subsequent slip is a consequence of the excess stress. A maximum mesh size of $7 \mathrm{~m}$ over the upper $30 \mathrm{~m}$ of the model is applied throughout to accommodate the mechanical response of annual temperature signals (although because of irregular topography and discontinuities the actual near-surface mesh size was 
Table 1

Mechanical and Thermal Properties of the Rock Mass Implemented in UDEC and COMSOL

\begin{tabular}{llcl}
\hline Mechanical properties (UDEC) & & & \\
\hline Density $\rho$ & $\left(\mathrm{kgm}^{-3}\right)$ & 2,700 & Wegmann (1998) \\
Poisson's ratio & () & 0.2 & Grämiger et al. (2017) \\
Young's modulus & $(\mathrm{GPa})$ & 30 & Grämiger et al. (2017) \\
Thermal expansion $\alpha$ & $\left(\mathrm{K}^{-1}\right)$ & $9.5 \times 10^{-6}$ & Keusen and Amiguet (1987) \\
Thermal properties (COMSOL) & $\left(\mathrm{W} \mathrm{m}^{-1} \mathrm{~K}^{-1}\right)$ & 2.9 & Wegmann et al. (1998) \\
Thermal conductivity $\lambda$ & $\left(\mathrm{J} \mathrm{kg}^{-1} \mathrm{~K}^{-1}\right)$ & 780 & Wegmann (1998) \\
Specific heat capacity at constant pressure $C_{P}$ & & &
\end{tabular}

frequently much smaller). We otherwise assign a mesh size of $20 \mathrm{~m}$ for the upper $300 \mathrm{~m}$ of the model, which increases stepwise at greater depths and beyond the area of interest.

We apply roller boundaries at the bottom and sides of our large-scale model (i.e., displacement is fixed normal to the boundary but free parallel to it; Figure 4). We model glacier loading as a hydrostatic stress boundary condition $\left(\rho_{\text {ice }}=917 \mathrm{~kg} \mathrm{~m}^{-3}\right.$ ) to account for the ductile nature of ice and its limited buttressing effect (Leith et al., 2014; McColl et al., 2010; McColl \& Davies, 2013). Basal shear stresses and spatial gradients in normal stress due to glacial slip are neglected. Initialization (Figure 4) is undertaken in the stepwise procedure described by Grämiger et al. (2017): Initial conditions represent the Aletsch Valley during the ice-free preLGM interglacial (Eemian) period. The initial far-field stresses represent combined exhumation-induced and tectonic stresses in a simplified paleo-alpine valley, with a horizontal to vertical stress ratio of $k=1$ (Kastrup et al., 2004). Plastic equilibration with these initial stresses results in an initial (inherited) damage field. We then add LGM ice and allow for subsequent damage. This represents the starting point for our transient TM models.

Heat flow in bedrock is controlled by rock surface temperatures, geothermal heat flux, and the thermal diffusivity of rock (e.g., Moore et al., 2011). Our assigned thermal properties are listed in Table 1. Heat transfer in our model occurs through conduction alone, defined by thermal diffusivity $D=\lambda\left(\rho C_{P}\right)^{-1}$, where $\lambda$ is thermal conductivity, $\rho$ is density, and $C_{P}$ is specific heat capacity at constant pressure. Heat advection by groundwater or air circulation in cracks is neglected, as well as any thermal effects of latent heat from melting ice or freezing water. Thermal conductivity is strongly dependent on porosity and pore filling, as well as joints in a rock mass (Moore et al., 2011). Wegmann (1998) measured the thermal conductivity and specific heat capacity for gneiss core samples from the nearby Jungfraujoch in similar lithology as in our study, obtaining $\lambda=2.9 \mathrm{~W} \mathrm{~m}^{-1} \mathrm{~K}^{-1}$ for dry rock and on average $C_{P}=780 \mathrm{~J} \mathrm{~kg}^{-1} \mathrm{~K}^{-1}$. We adopted these values in our COMSOL models (Table 1), which are in close agreement with other past studies (Eppelbaum et al., 2014; Rybach \& Pfister, 1994; Waples \& Waples, 2004). Together, these parameters result in a thermal diffusivity of $D=1.4 \times 10^{-6} \mathrm{~m}^{2} \mathrm{~s}^{-1}$ (cf. Gischig et al., $2011 \mathrm{~b}$; Moore et al., 2011). The modeled depth of the thermally active layer matches long-term temperature measurements from a nearby $10-\mathrm{m}$ deep borehole at Eggishorn (Luethi \& Phillips, 2016). Our thermal properties and model boundary conditions yield a geothermal gradient of

Table 2

Discontinuity Properties for the Mohr-Coulomb Constitutive Law Including Slip-Weakening Implemented in UDEC (Grämiger et al., 2017)

\begin{tabular}{llcccc}
\hline Discontinuity parameters & \multicolumn{1}{c}{ Unit } & Intact rock (Voronoi) & F1 foliation & F3 & F4 faults \\
\hline Peak friction angle $\varphi$ & $\left(^{\circ}\right)$ & 50 & 33.7 & 37.2 & 27 \\
Peak cohesion $c$ & $(\mathrm{MPa})$ & 8 & 1.8 & 3.5 & 0.03 \\
Peak tensile strength $t$ & $(\mathrm{MPa})$ & 1 & 0.4 & 0.8 & 0 \\
Residual friction angle $\varphi_{R}$ & $\left({ }^{\circ}\right)$ & 27 & 27 & 27 & 27 \\
Residual cohesion $c_{R}$ & $(\mathrm{MPa})$ & 0.03 & 0.03 & 0.03 & 0.03 \\
Residual tensile strength $t_{R}$ & $(\mathrm{MPa})$ & 0 & 0 & 0 & 0 \\
Dilation angle & $\left({ }^{\circ}\right)$ & 5 & 5 & 5 & 5 \\
Dip angle & $\left({ }^{\circ}\right)$ & & 75 & 6 & 75 \\
Normal stiffness $k_{n}$ & $\left.(\mathrm{GPa} \mathrm{m})^{-1}\right)$ & 20 & 5 & 10 & 1 \\
Shear stiffness $k_{s}$ & $\left.(\mathrm{GPa} \mathrm{m})^{-1}\right)$ & 10 & & 5 & 0.5 \\
\hline
\end{tabular}



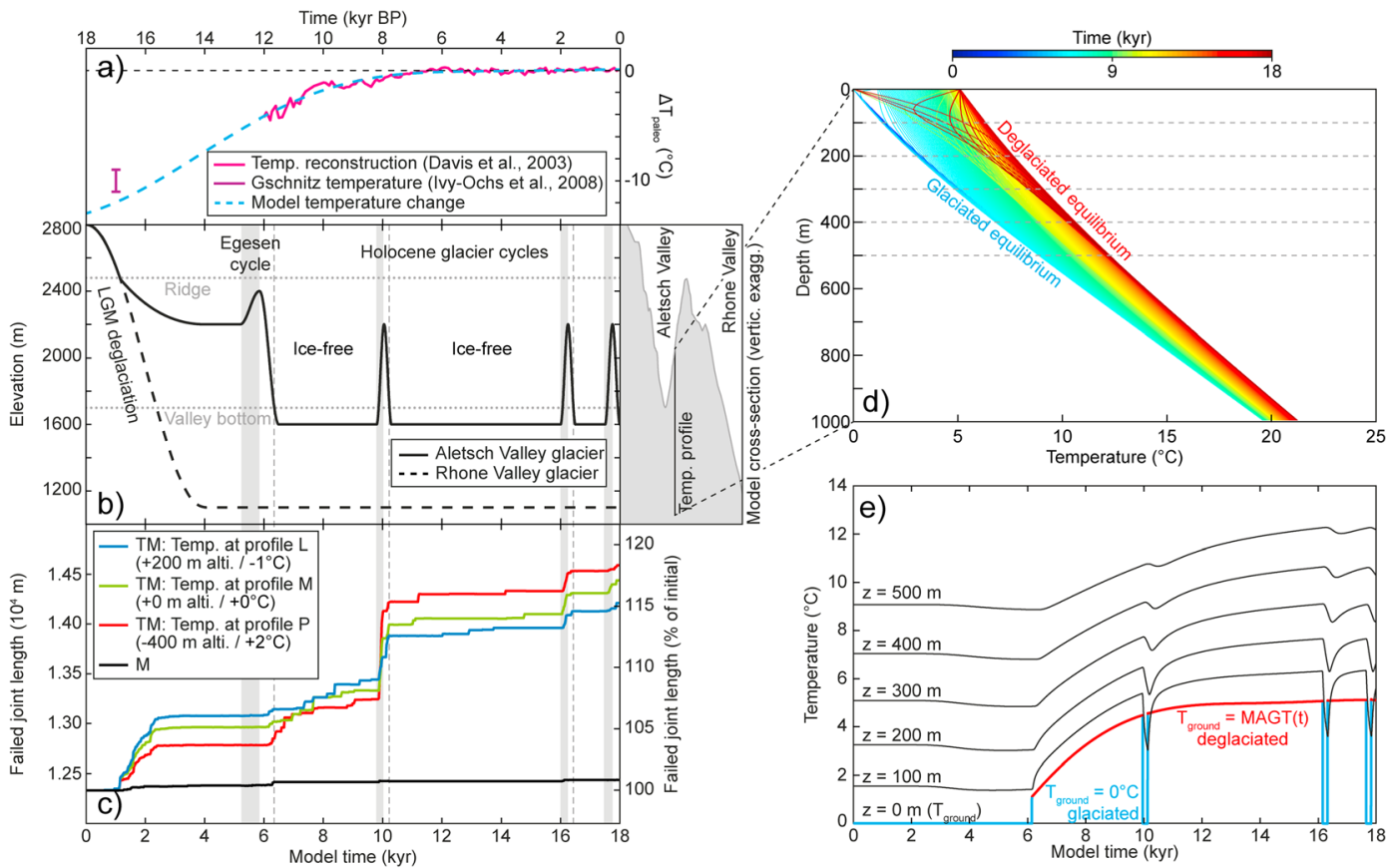

Figure 5. Transient rock slope damage during repeat glacial cycles in concert with long-term thermomechanical effects induced by Late Glacial/Holocene temperature change: (a) applied model temperature change relative to present fitting paleotemperature reconstructions (Davis et al., 2003; Ivy-Ochs et al., 2008). (b) Applied glacier scenario with compressed profile $\mathrm{M}$ for reference. (c) Temporal evolution of damage for applied temperature scenarios, illustrated as the sum of failed joint length and percentage of initial damage, in comparison to a purely mechanical (M) model. (d) Temperature change with depth at time steps of 50 years for temperature profile in cross section over $18 \mathrm{kyr}$. (e) Corresponding temperature change over time at different depths in the temperature profile and surface temperature signal $\left(T_{\text {ground }}\right)$.

$\sim 21{ }^{\circ} \mathrm{C} \mathrm{km}^{-1}$ (see Figure 5), similar to a reported geothermal gradient of $23{ }^{\circ} \mathrm{C} \mathrm{km}^{-1}$ in the Aar massif by Rybach \& Pfister (1994). TM strain in our model results from a thermal expansion coefficient $\alpha$ of $9.5 \times 10^{-6} \mathrm{~K}^{-1}$ (Keusen \& Amiguet, 1987) assigned to elastic blocks between discontinuities, a value similar to that used by Gischig et al. (2011a).

Temperature fields for each mechanical equilibrium step of our transient models were calculated in COMSOL. A fine mesh size of maximum $3 \mathrm{~m}$ in the upper $20 \mathrm{~m}$ and small time step for the solver ( $<0.05$ year) were used to accommodate annual temperature signals. Thermal boundary conditions throughout the transient model are tied to the fluctuating glacier elevation (Figure 4). Below the glacier, temperatures are held constant at $0{ }^{\circ} \mathrm{C}$, while above the ice, rock surface temperatures are influenced by ambient environmental conditions (Gruber et al., 2004). In our models, rock surface temperate boundary conditions vary with altitude, time, and glacier elevation as

For $z \leq$ glacier elevation $(t)$ :

$$
\begin{gathered}
T(t, z)=0 \\
T(t, z)=\operatorname{MAGT}(t, z)+A \sin (2 \pi f t) \\
\operatorname{MAGT}(t, z)=15.3-0.005(z)+\Delta T_{\text {paleo }}(t)
\end{gathered}
$$$$
\text { For } z>\text { glacier elevation }(t) \text { : }
$$

where

The assigned temperatures represent superposition of the MAGT and a sinusoidal annual signal of amplitude $A$. Thermal boundary conditions above the ice are based on our in situ rock temperature measurements at the Aletsch Glacier (see Appendix A1 and Figure A1). MAGT depends on the lapse rate (here $0.005^{\circ} \mathrm{C} \mathrm{m}^{-1}$ ), temperature of $15.3^{\circ} \mathrm{C}$ at the reference elevation of $z=0 \mathrm{~m}$ and the paleo-temperature change relative to present $\left(\Delta T_{\text {paleo }}\right)$. Annual amplitude was approximated as independent of altitude or aspect as $A=10{ }^{\circ} \mathrm{C}$ (for discussion see Appendix A1). Zero-flux boundary conditions define the sides of the model, while a geothermal heat flux of $Q_{\text {geotherm }}=60 \mathrm{~mW} \mathrm{~m}^{-2}$ is applied at the bottom (Wegmann et al., 1998, and references therein). 
Following each mechanical time step in UDEC, the temperature field computed in COMSOL is interpolated on the mesh of the UDEC model. Here discontinuities are ignored; that is, the rock mass is considered to be continuous in that the temperature gradient across discontinuities corresponds to a conductive temperature field without material contrasts (Itasca, 2014). Thus, the interpolated temperature field is used to compute strains and stresses corresponding to mechanical equilibrium. Further insights into the implementation of TM coupling are given in Appendix A2. To compute mechanical equilibrium, UDEC uses a damped timestepping scheme that seeks to reduce unbalanced forces in the model domain.

Modeling the Aletsch Valley throughout the Late Glacial and Holocene ( $18 \mathrm{kyr})$ including annual temperature cycles required unfeasibly large computation times of several weeks. Therefore, we divided our modeling strategy into two parts: (1) long-term TM effects during the Late Glacial and Holocene not including annual cycles and (2) TM effects resulting from annual temperature and glacial cycles over a shorter time period. The first suite of models cover the entire Late Glacial/Holocene period allowing long-term temperature changes (i.e., Holocene warming and bedrock exposure during deglaciation) to diffuse at depth. To capture the long-term response, it is important to initiate the model with a realistic temperature field. Our initial temperature conditions start under LGM ice occupation at the same point as our transient TM models. We assume thermal steady state at the LGM, representing a period of sustained ice cover during the last glacial period. Thermal boundary conditions and the initial temperature field with LGM ice cover are shown in Figure 4. Mechanical equilibrium is calculated in time steps of 2 years in our long-term models. From simple 1-D thermal diffusion theory with oscillatory boundary conditions, we can readily derive the characteristic depth $Z_{\text {char }}$ at which a surface temperature disturbance $\Delta T$ has decayed to $\Delta T / e$. The simple relationship is $Z_{\text {char }}=\sqrt{D P / \pi}$, where $P[\mathrm{~s}]$ is the period, indicating that the depth to which temperature signals reach increases as the square-root of period (e.g., Anderson \& Anderson, 2010). In our long-term models, $P$ is $100-1,000$ years, yielding $Z_{\text {char }}$ of $\sim 40-120 \mathrm{~m}$.

In our second suite of models, we investigate annual TM cycles affecting the rock mass together with fluctuating ice loads. Modeling annual cycles throughout 18 kyr was not feasible due to long computation times. Therefore, we distribute 500 annual temperature cycles over the same glacier scenario applied in the longterm TM models. We argue that this simplification is appropriate to explore the effects of TM cycling because a rock mass requires $\sim 5$ years to accommodate new cyclic thermal boundary conditions (Gischig et al., 2011a). In our modeled Late Glacial/Holocene glacier scenario (see Figure 5b), long periods of several thousand years with constant glacier ice or ice-free conditions prevail, when only TM cycling affects the bedrock. Since after $\sim 5$ years, TM cycling is relatively insignificant, decreasing the number of TM cycles throughout our glacier scenario presents a reasonable modeling simplification. On the other hand, long-term temperature effects from the presence or absence of ice cover are inadequately simulated over the shortened time span. Therefore, we neglect long-term temperature changes by initiating an overall $0{ }^{\circ} \mathrm{C}$ background temperature and assigning zero-flux boundary conditions at the model sides and bottom. We apply only annual temperature cycles assuming $A=10^{\circ} \mathrm{C}$ and MAGT $=0{ }^{\circ} \mathrm{C}$. Lapse rate and paleo-temperature effects are omitted. In this second series of simulations, mechanical equilibrium is calculated in time steps of 0.1 years to accommodate the annual temperature signal. Note that annual cycles reach characteristic depths of about $4 \mathrm{~m}$, while for the long-term cycles compressed to 100-year periods (instead of $\sim 1,000$ years), it is $\sim 40 \mathrm{~m}$, thus underestimating the depth reached by the actual long-term cycles.

\subsection{Long-Term Thermomechanical Effects}

The presence or absence of ice cover affects the bedrock temperature field during glacial cycles; here we explore TM rock slope damage induced by long-term temperature changes (Figure 5). We quantify damage (here and in subsequent models) as the cumulative length of all failed joints. Initial stresses and temperatures are applied as described previously (Figure 4). We model $18 \mathrm{kyr}$ of simplified Late Glacial and Holocene ice fluctuations. Our applied paleotemperature change relative to the present MAGT ( $\left.\Delta T_{\text {paleo }}\right)$ matches past air temperature reconstructions (Davis et al., 2003; Ivy-Ochs et al., 2008; Figure 5a). Rock surface temperatures below ice are held constant at $0{ }^{\circ} \mathrm{C}$, and above ice MAGT is a function of time and elevation (equation (4) and Figure 5e). This model does not include annual cycles. The applied hydrostatic glacier loading scenario (Figure $5 \mathrm{~b}$ ) is based on mapped ice extents along profile $\mathrm{N}$ (Figure 2), whereas the timing and number of Late Glacial/Holocene ice fluctuations is simplified (see Figure 3). This glacier scenario was selected to simulate the largest changes in ice elevation, with ice-free conditions between glacier advances. We included 

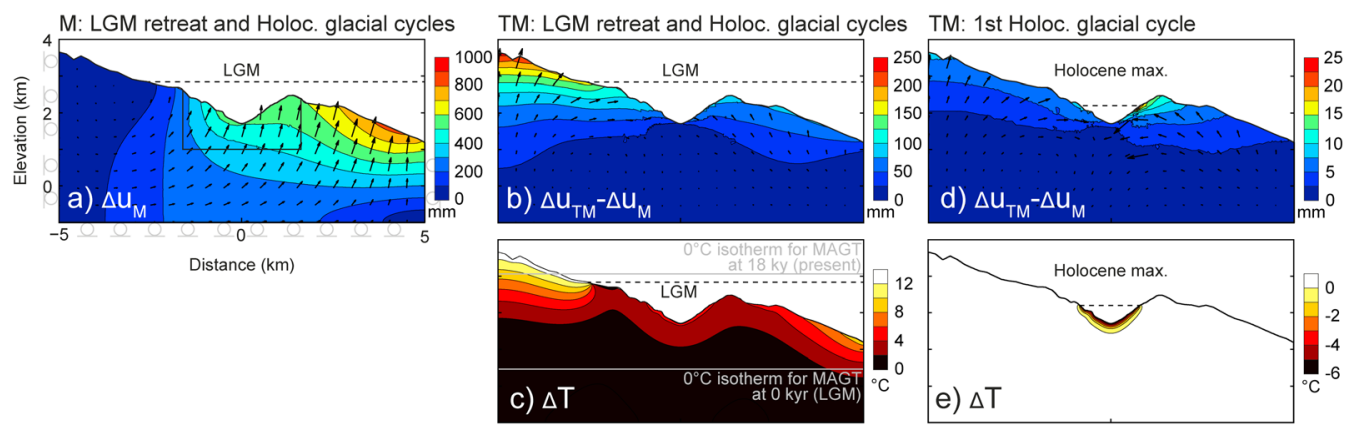

Figure 6. Thermomechanical (TM) reaction of the full model ( $+0-\mathrm{m}$ altitude $/+0{ }^{\circ} \mathrm{C}$ scenario): (a) maximum displacement $(\Delta u)$ as a result of purely mechanical $(\mathrm{M})$ unloading and loading during Last Glacial Maximum (LGM) deglaciation and Holocene glacial cycles. (b) Additional TM displacement induced by temperature change during LGM deglaciation and Holocene glacial cycles. (c) Temperature change during LGM deglaciation and Holocene cycles (18 kyr) with changing $0{ }^{\circ} \mathrm{C}$ isotherm for MAGT at 0 and $18 \mathrm{kyr}$. (d) Additional TM displacement induced by temperature change during the first Holocene glacial cycle. (e) Temperature change during first Holocene cycle.

three variations in model temperatures representing the same cross-profile at different altitudes (corresponding to profiles $L, M$, and $P$ in Figure 2). Profile $M$ represents the actual altitude of the model cross section. Profile $L$ is $200 \mathrm{~m}$ higher therefore MAGT is $1{ }^{\circ} \mathrm{C}$ cooler, while profile $P$ is $400 \mathrm{~m}$ lower resulting in a $2{ }^{\circ} \mathrm{C}$ increase in MAGT.

Last Glacial Maximum deglaciation and subsequent Holocene glacial cycles affect the temperature regime in the subsurface on kyr time scales (Figures $5 \mathrm{~d}$ and $5 \mathrm{e}$ ). The equilibrated LGM geothermal gradient is disturbed by rock surface exposure to varying MAGT conditions. The temperature signal diffuses downward, shifting the thermal gradient to a new equilibrium under deglaciated conditions (Figure 5d). Concurrently, MAGT increases with time. Short interludes of 500 years of ice cover during the Holocene disturb temperatures in the uppermost $200 \mathrm{~m}$ of the slope by several degrees, marked by a sudden onset, while the temperature response at larger depths is smaller and delayed (Figure 5e).

Surface and subsurface temperature changes result in TM rock slope damage, expressed as the sum of failed joint length and compared to a purely mechanical model (Figure 5c). A joint fails when stresses reach the failure criterion, allowing for irreversible displacement, and strength properties drop from peak to residual values. After Egesen deglaciation, damage accumulation persists for $\sim 3 \mathrm{kyr}$ between $\sim 6.5$ - and 9.5-kyr model time even though the slope remains ice-free and is unaffected by changing glacier load. MAGT increases by up to $4{ }^{\circ} \mathrm{C}$ during this time (Figure 5a). The greatest damage increment occurs at the onset of the first Holocene glacier advance around $\sim 10 \mathrm{kyr}$ in the model. Later glacial cycles at $\sim 16$ - and $\sim 17.5$-kyr model time generate less damage. The purely mechanical model results in only $\sim 1 \%$ additional damage compared to the initial damage field (i.e., inherited damage from the ice-free pre-LGM period and subsequent LGM ice loading). Including long-term TM effects induced by glacier fluctuations generates between $\sim 15 \%$ and $19 \%$ additional damage. The differences in total damage between the three model scenarios are small and driven by the temperature contrast between the glacier $\left(0^{\circ} \mathrm{C}\right)$ and MAGT (larger temperature changes result in larger thermal strain). The low-elevation scenario (profile P) experiences the greatest warming from initially $0{ }^{\circ} \mathrm{C}$ to ice-free conditions, thereby generating the most damage during the first glacier advance $(\sim 10-\mathrm{kyr}$ model time) as ice cools the bedrock. Temperatures at profile $L$ are closer to $0{ }^{\circ} \mathrm{C}$, and therefore, temperature changes with glacier cycles are smaller, generating less damage. Warming of only a few degrees in the upper part of the slope after deglaciation is sufficient to induce incremental damage, even in the absence of changing glacier load. Glacier advances are more effective in generating rock slope damage in connection with cooling of bedrock beneath the ice.

Thermomechanical strains for the full model shown in Figure 6 help explain observed new damage. LGM deglaciation and Holocene cycles in a purely mechanical model result mostly in elastic postglacial rebound due to ice unloading (Figure 6a). However, long-term temperature changes associated with a complete glacial cycle generate significant additional TM displacement (Figure 6b). The magnitude of additional displacement scales with temperature change since the LGM (Figure $6 c$ ). The high-altitude western slope above LGM ice is exposed to MAGT conditions at all times, experiencing the entire modeled temperature increase of up 


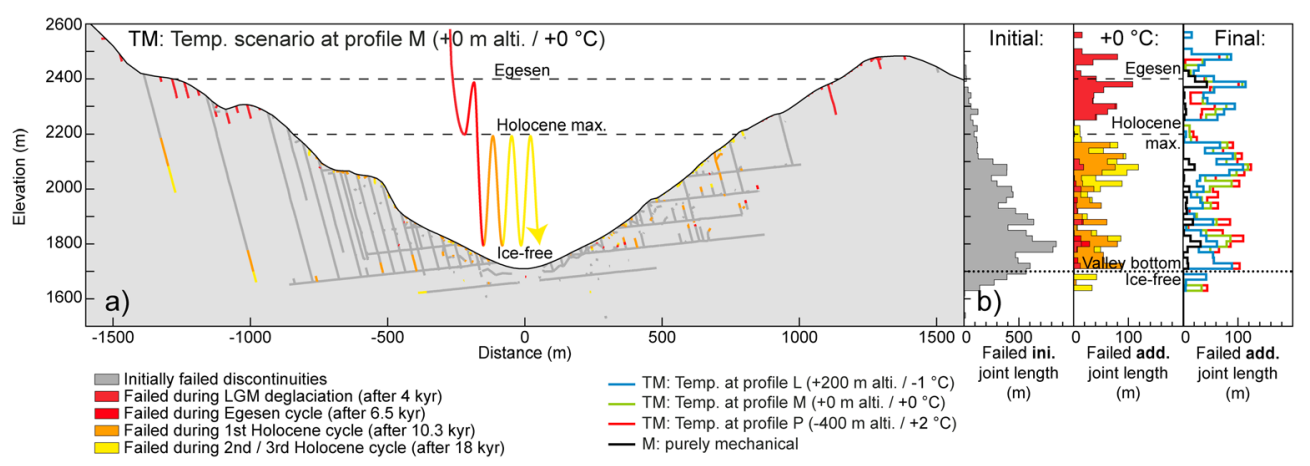

Figure 7. Influence of long-term temperature change on rock slope damage during repeat glacial cycles: (a) spatial and temporal distributions of thermomechanical damage for the temperature scenario at profile $M$ in the cross section. (b) Damage elevations at initial conditions, additional damage with time for the temperature scenario at profile $M$, and final additional damage for different temperature scenarios in comparison with a purely mechanical $(M)$ model displayed as histogram.

to $\sim 12{ }^{\circ} \mathrm{C}$. The $0{ }^{\circ} \mathrm{C}$ annual isotherm rises during the model run from initially 465 to $3,060 \mathrm{~m}$. Bedrock in our area of interest becomes exposed to ambient temperatures for the first time after $\sim 6 \mathrm{kyr}$, when modeled temperature change relative to today is comparably small (see Figure 5a). Bedrock warming in this area is mostly related to the temperature contrast between ice and the MAGT. Temperature changes at the surface diffuse at depth, and the long-term temperature increase accompanying with deglaciation contributes to greater elastic rebound (Figures $6 a$ and $6 \mathrm{~b}$ ). Subsequent ice readvance cools underlying bedrock and the uppermost $\sim 200 \mathrm{~m}$ of the slope by several degrees (Figure 6e). Thermal strain results in additional displacement affecting both valley flanks, but the eastern slope with toppling mode rock structure shows enhanced movement of up to $\sim 25 \mathrm{~mm}$ (Figure 6d). Spatial differences in ground temperature change result on the one hand from MAGT warming through the Late Glacial and Holocene, and on the other hand from a change in the thermal boundary conditions during ice retreat. Cooling within the Aletsch Valley during ice advance leads to thermal contraction of the rock mass, reducing joint normal stresses along steeply dipping discontinuities and promoting toppling (Gischig et al., 2011a; Watson et al., 2004). On the other hand, thermal expansion is redirected by lateral confinement into elastic rebound and increases stresses.

Thermomechanical strains can create stress concentrations leading to failure of critically stressed discontinuities. The influence of long-term temperature change on rock slope damage during repeat glacial cycles is presented in Figure 7, which shows the spatial and temporal TM damage distributions. Rock slope damage induced in a purely mechanical model is minor (Figure 7b), whereas including long-term changes in thermal boundary conditions leads to significant new damage accumulation with glacial cycles. First deglaciation after the LGM and Egesen generates damage in the upper $100 \mathrm{~m}$ on the valley shoulders (Figure 7a). Subsequent Holocene glacier cycles produce damage in deeper areas, propagating preexisting failed discontinuities. Differences in damage between the three variations in model temperatures are small (Figure 7b).

\subsection{Annual Thermomechanical Effects}

Here we investigate how annual temperature cycles interact with a fluctuating glacier to generate TM damage. We begin by applying surface temperature cycles in a purely elastic medium to visualize the conductive temperature field and elastic stress and displacements induced (Figure 8). We used an identical model geometry and initialization procedure as for our long-term TM models (see Figure 4) and applied thermal conditions as described previously, initiating a uniform $0{ }^{\circ} \mathrm{C}$ background temperature and applying sinusoidal annual surface temperatures around this mean value $\left(A=10^{\circ} \mathrm{C}\right.$; MAGT $\left.=0{ }^{\circ} \mathrm{C}\right)$. Glacier elevation remained constant in this first test, lapse rate, and paleo-temperature changes were omitted. Rock surface temperature boundary conditions below ice were $0{ }^{\circ} \mathrm{C}$, while temperatures above ice were a function of time (equation (3)).

The annual temperature signal decays in the upper $\sim 10 \mathrm{~m}$, and peak-to-peak displacements at $3 \mathrm{~m}$ depth are in the submillimeter range (Figure 8 ). The eastern and western slopes move $\sim 0.5-\mathrm{mm}$ inward toward the 

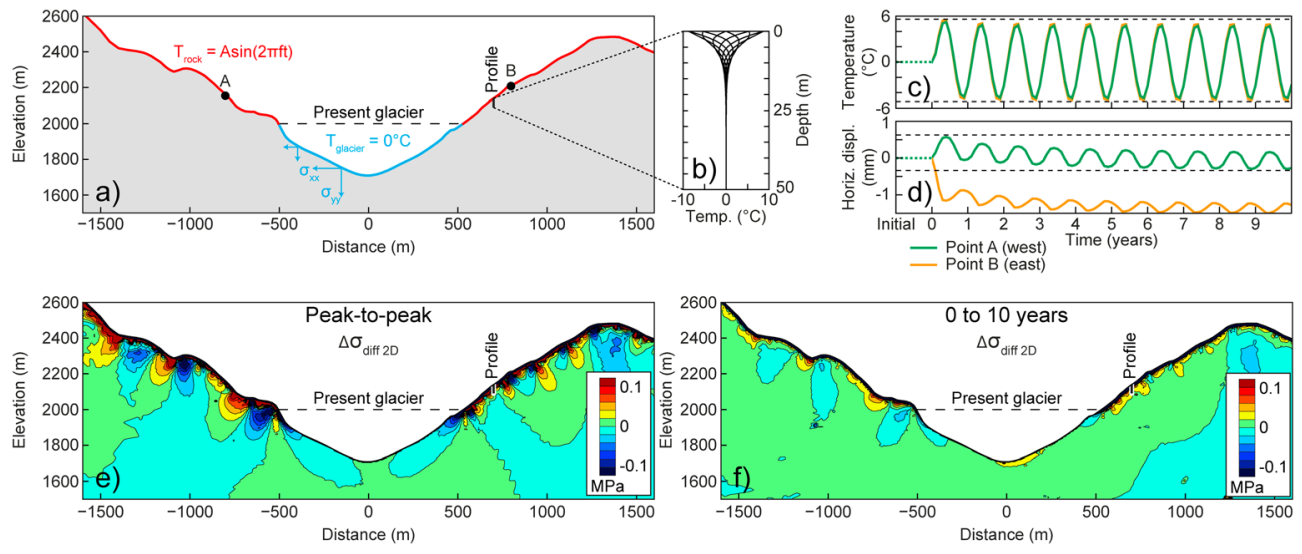

Figure 8. Elastic effects of seasonal temperature cycles in a glacial environment: (a) thermal and stress boundary conditions of the model with constant glacier at present-day level. Constant $0{ }^{\circ} \mathrm{C}$ below ice and annual temperature cycles above the ice. Location of observation points at $3 \mathrm{~m}$ depth. (b) Decreasing peak-to-peak amplitude of temperature cycle with depth. (c) Temperature change at observation points. (d) Horizontal displacement at observation points showing irreversible deformation due to paraglacial thermal shock within 10 annual cycles. Valley opening and closing of $\sim 1 \mathrm{~mm}$ with annual thermal cycles. (e) Peak-to-peak in-plane differential stress in 10th cycle. (f) In-plane differential stresses after 10 annual cycles showing induced stress by thermal shock.

valley during warming and outward during cooling (Figure $8 \mathrm{~d}$ ). This antipodal movement results in annual valley opening and closing of $\sim 1 \mathrm{~mm}$ from thermal strain. Warming also leads to upward displacement, while cooling results in downward displacement of similar magnitude. The multiyear trend of displacements shown in Figure 8d reflects the transient effect of applying a new temperature fluctuation to the model and requires approximately 5 years to reach quasi-static equilibrium (termed thermaltransient phase by Gischig et al., 2011a). Thermal strain in the near-surface induces differential stress changes up to a few hundred $\mathrm{kPa}$, which propagate to depths below the thermally active layer (Figure $8 \mathrm{e}$ ). TM-induced stresses are strongly affected by topography (Harrison \& Herbst, 1977). Figure 8 f shows differential stress changes after 10 TM cycles, representing induced stresses resulting from accommodation of new cyclic thermal boundary conditions. Maximum stresses are in the range of $\sim 100 \mathrm{kPa}$ in the upper $50 \mathrm{~m}$.

In the following models, we combine annual TM cycles with fluctuating ice loads, where transient thermal boundary conditions are tied to the changing glacier elevation (Figure 9). Five hundred annual cycles run together with applied glacier scenarios N and P (adopted from Grämiger et al., 2017 and based on mapped glacier extents along profiles shown in Figure 2), comparing an alpine valley undergoing LGM deglaciation with three subsequent Holocene glacial cycles (scenario N), to LGM deglaciation followed by a minor Egesen advance and retreat and subsequent ice-free Holocene conditions (scenario P; Figure 9a).

Thermomechanical cycles combined with repeat glaciation generate rock slope damage (Figure 9b). Major damage accumulation occurs during first deglaciation, when bedrock is first exposed to annual temperature cycles. In scenario $\mathrm{P}$ this occurs between $\sim 30$ and 50 TM cycles. In scenario $\mathrm{N}$, major damage occurs within $\sim 100$ cycles, when the upper rock slope is first exposed, and again between $\sim 150$ and 200 cycles as the lower rock slope is deglaciated for the first time. Both scenarios reach a similar damage level, although subsequent Holocene cycles in scenario $\mathrm{N}$ generate slightly more damage. Figure $9 \mathrm{c}$ highlights new damage occurring during the Holocene. In scenario P, TM stress cycles are capable of inducing minor rock slope damage even after several hundred cycles and in the absence of changing glacier load. New damage during Holocene glacial cycles in scenario $\mathrm{N}$ occurs mainly during glacier advances, similar to our purely mechanical models (Grämiger et al., 2017). However, including TM effects leads to increased damage accumulation, which is larger than the simple addition of purely mechanical damage and the damage of annual TM cycles during ice-free conditions (Figure 9c). These results demonstrate that glacial and TM cycles combine to enhance rock slope damage. Purely mechanical models resulted in only $\sim 1 \%$ additional new damage (Figure 9b), whereas new TM damage in scenario $\mathrm{P}$ reached $\sim 10 \%$ and with subsequent Holocene cycles in scenario $\mathrm{N} \sim 11 \%$ (the corresponding long-term TM scenario resulted in 17\%). TM damage during subsequent Holocene cycles is observed but is minor compared to damage during first-time retreat. The first adaption to new thermal 

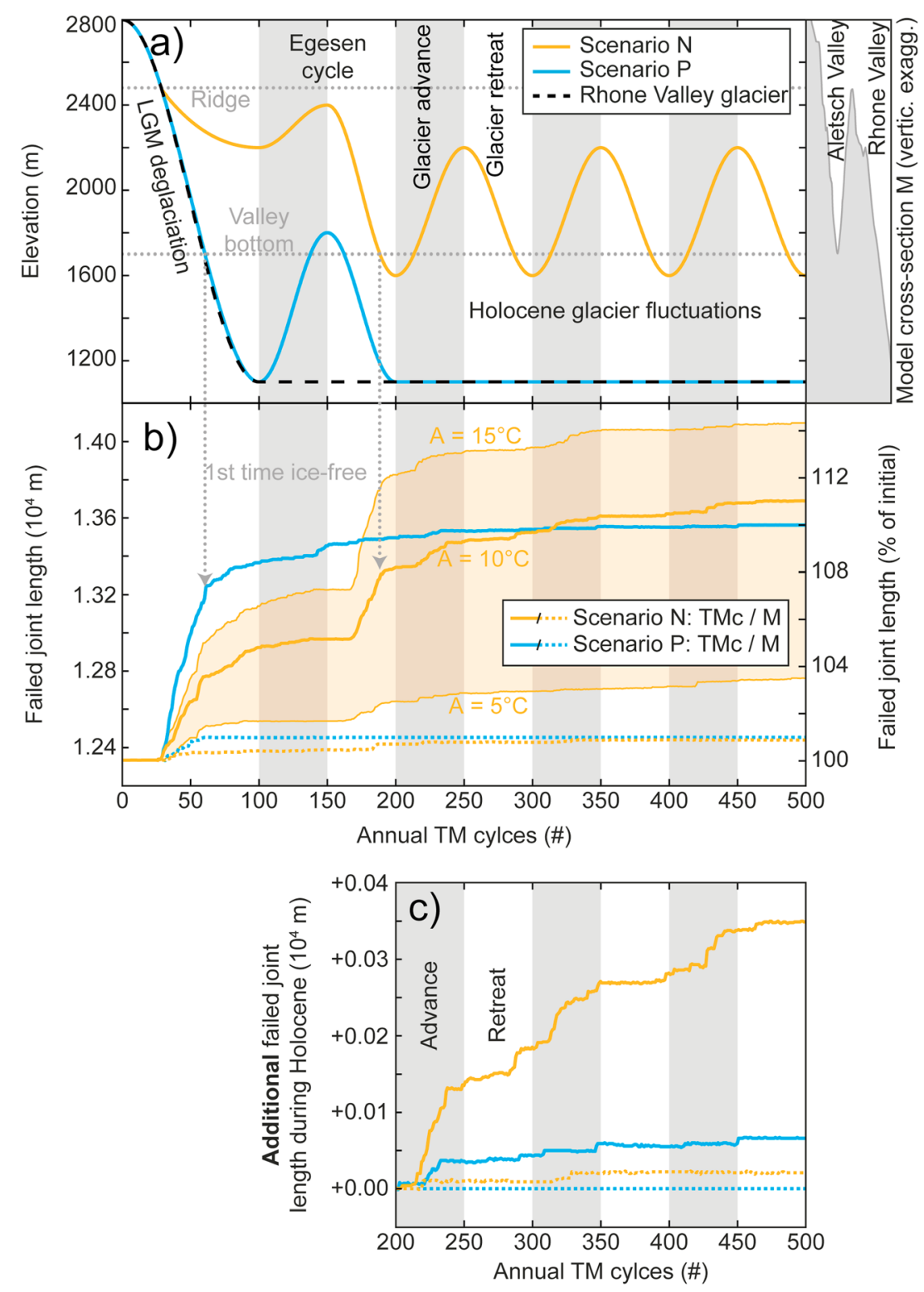

Figure 9. Transient rock slope damage during repeat glacial loading in concert with thermomechanical effects induced by annual temperature cycles (TMc): (a) applied glacier scenarios based on mapped extents along profiles $\mathrm{N}$ and $\mathrm{P}$ (see Figure 2) with compressed profile $M$ as reference. (b) Temporal evolution of damage for applied glacier scenarios illustrated as the sum of failed joint length and percentage of initial damage, each in comparison to purely mechanical (M) models. Amplitude of annual temperature cycle applied in scenario $\mathrm{N}$ varies between 5,10 , and $15^{\circ} \mathrm{C}$. (c) Additional failed joint length during the Holocene compared in scenarios with (orange) and without (blue) Holocene cycles (each TMc/M).

boundary conditions causes greatest damage, although subsequent TM cycles result in ongoing minor damage. Annual TM cycles are thus a significant driver of paraglacial rock slope damage, but the effect of thermal shock is restricted to first-time deglaciation. Induced damage strongly depends on the amplitude of the applied annual temperature cycle (Figure 9b).

Spatial and temporal distributions of rock slope damage induced by seasonal TM cycles in conjunction with glacier fluctuations are shown in Figure 10. New damage occurs mainly in the upper 20-30 m, covering mostly the upper slope (Figures 10a and 10b). However, incremental damage also accumulates at greater depths in the form of fracture propagation along initially failed discontinuities. Detailed analysis of the eastern upper slope shows how a damage front propagates with glacier retreat due to paraglacial thermal shock 


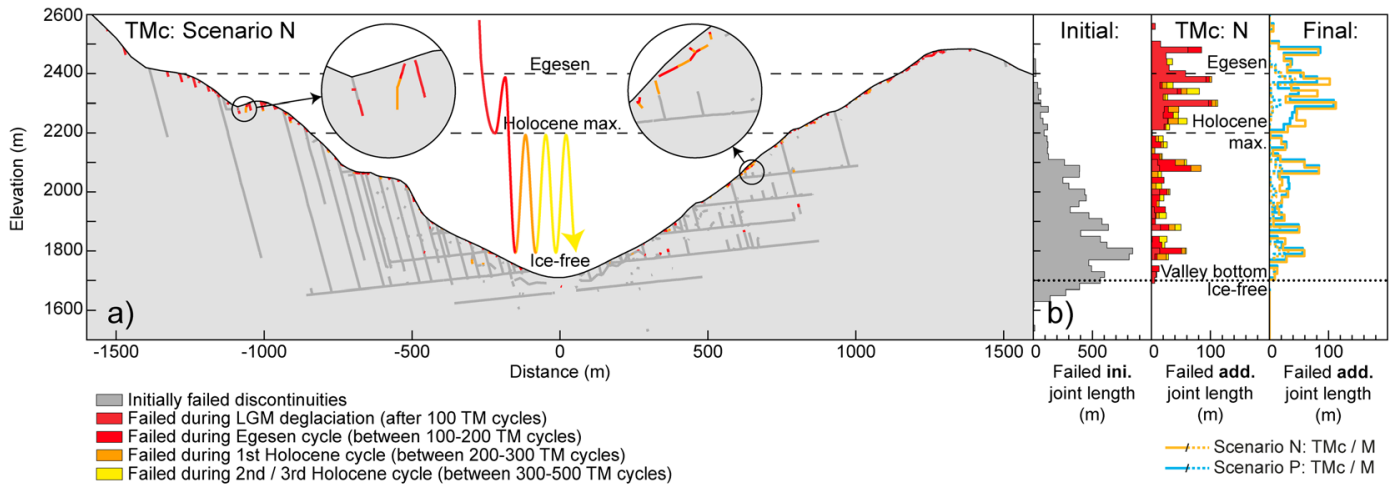

c) M: Deglaciation in scenario $P$
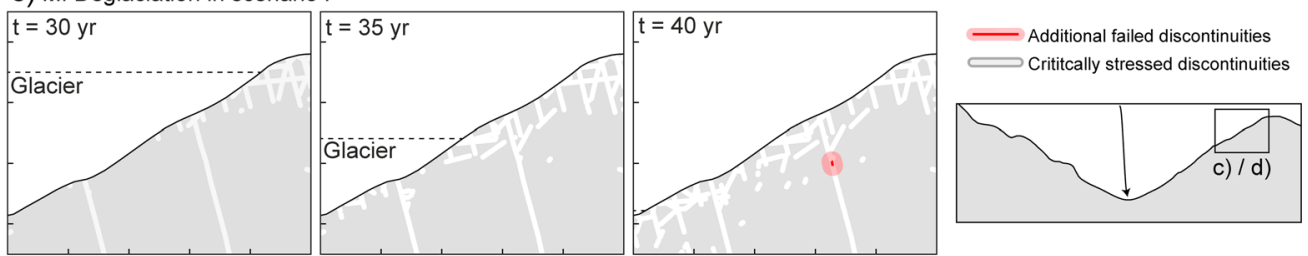

d) TMc: Deglaciation in scenario $P$

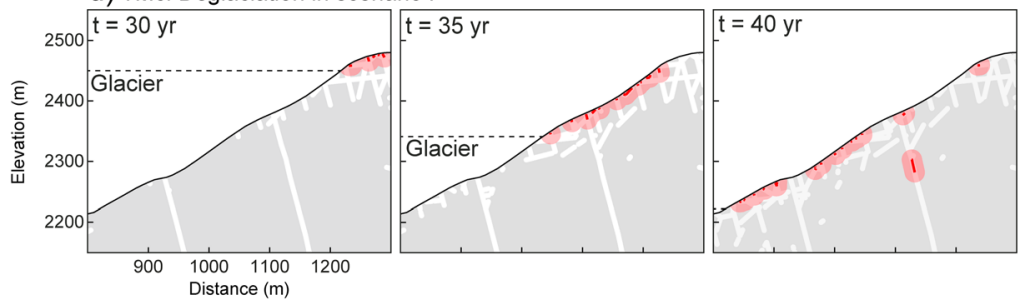

Figure 10. Influence of seasonal thermomechanical (TM) cycles on rock slope damage during repeat glacial cycles: (a) spatial and temporal distributions of damage induced by TM stress cycles (TMc) for model scenario N in the cross section. (b) Damage elevations at initial conditions, additional damage with time for scenario $\mathrm{N}$ induced by TMc, and final additional damage for scenarios $\mathrm{N}$ and $\mathrm{P}$ (each TM/M) displayed as a histogram. (c) Rock slope damage evolution during 10 years of deglaciation for scenario P displaying additional failed discontinuities and critically stressed joints (here defined as within 2 MPa of the Mohr-Coulomb failure criterion) for a purely mechanical (M) model. (d) Rock slope damage evolution during 10 years of deglaciation with annual TMc showing a shallow damage front propagating with glacier retreat by thermal shock.

(Figures 10c and 10d). Glacier retreat changes the stress state of discontinuities in the slope. A zone of critically stressed discontinuities (here defined as within $2 \mathrm{MPa}$ of the Mohr-Coulomb failure criterion) follows the decreasing glacier elevation. Below the glacier, discontinuities are less critically stressed due to increased normal stresses from the weight of ice. Decreasing normal stresses accompanying ice loss brings stress conditions closer to failure. In a purely mechanical model, an increase in the amount of critically stressed joints leads to only minor additional damage (Figure 10c). However, including seasonal TM cycles in addition to glacier retreat introduces new damage. The damage front follows glacier retreat and is mainly shallow, restricted to the upper 20-30 m, with annual temperature changes reaching depths of $\sim 10 \mathrm{~m}$.

We compare new damage and displacement along discontinuities during one Holocene glacial cycle for a purely mechanical model and for a TM model including annual cycles (Figure 11). Mechanical loading during glacier advance leads to downward displacement of the valley, which is expressed as right-handed movement in the west and left-handed movement on the eastern slope along steeply dipping discontinuities below the glacier (Figure 11a). On the other hand, steep joints on the eastern valley flank above the glacier undergo right-handed shearing during advance, promoting toppling and new damage. A reversed sense of slip is observed during glacier retreat. This reversible joint displacement amounts to a few millimeters. Irreversible joint slip over the glacial cycle is restricted to the eastern slope at the valley bottom and midslope region, showing toppling mode kinematics. Incorporating annual TM cycles in combination with the glacier loading cycle results in a similar pattern of shear dislocation, and new damage is increased but 


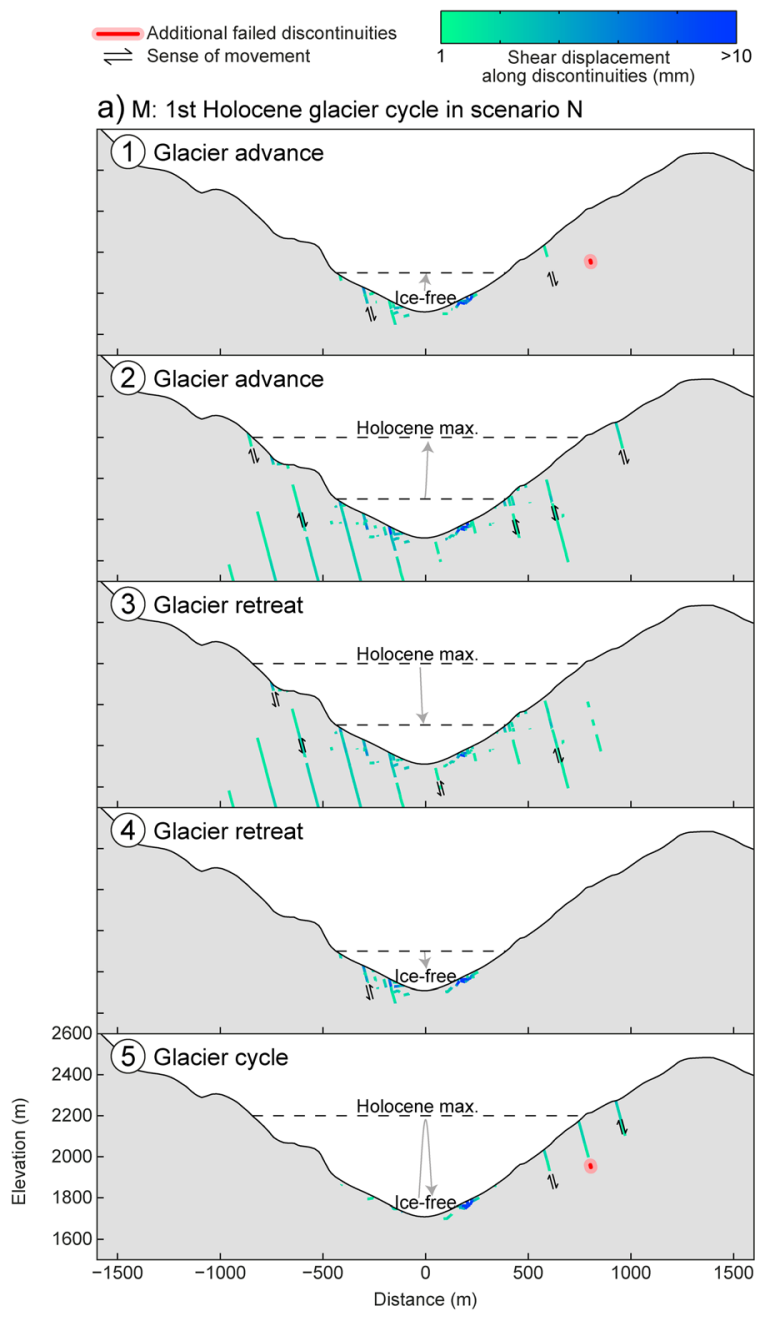

b) TMc: 1st Holocene glacier cycle in scenario $\mathrm{N}$
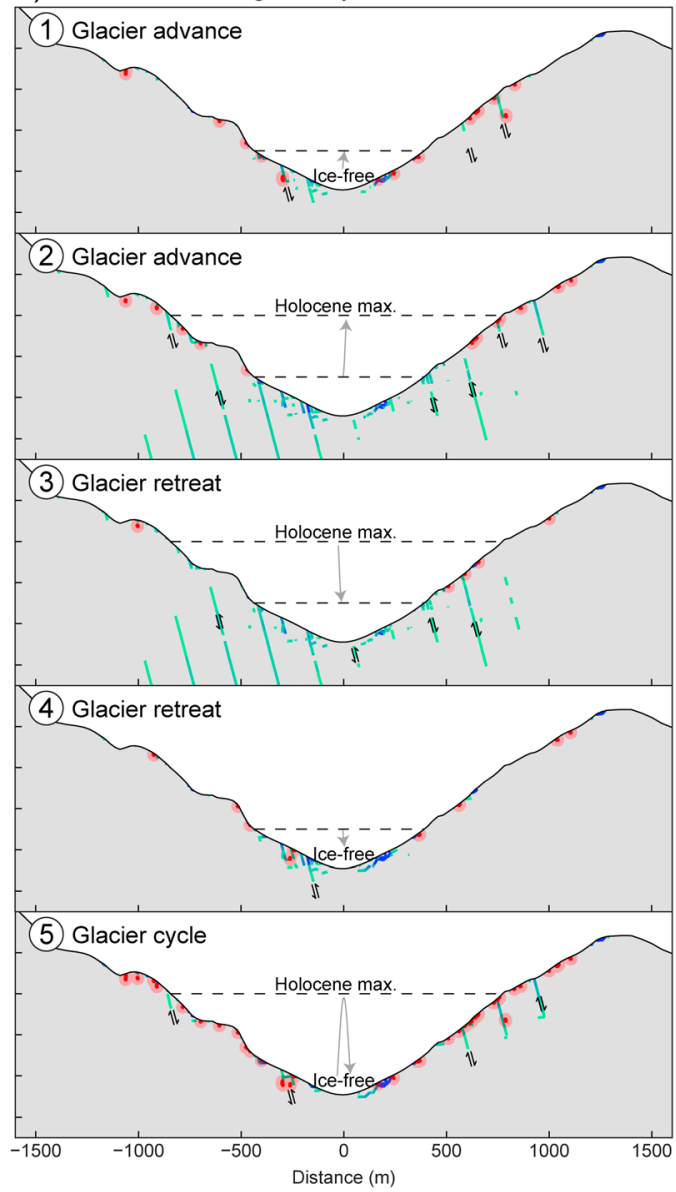

Figure 11. Shearing and damage during one glacial cycle: (a) shear displacement along discontinuities during the first Holocene cycle for model scenario $\mathrm{N}$ in a purely mechanical (M) model and (b) with thermomechanical stress cycles (TMc) included.

predominantly shallow (Figure $11 \mathrm{~b}$ ). Note that the valley flanks presented in Figure $11 \mathrm{~b}$ have already experienced thermal shock during LGM deglaciation. Glacier advance generates more damage than glacier retreat. TM models produce displacement along steeply dipping discontinuities on the western slope not observed in our purely mechanical models (Figure 11).

\subsection{Influence of Initial Rock Mass Strength}

Thermomechanical effects vary with assumed rock mass strength and in turn on the amount of critically stressed discontinuities (Gischig et al., 2011a). Damage effects from TM and mechanical models are both anticipated to be stronger for increased criticality of the slope (Grämiger et al., 2017). Here we apply our TM model to a weakened slope, that is, one with reduced rock mass strength. We performed a series of simulations varying initial rock mass strength while keeping initial stress conditions constant. We reduced peak strength properties (friction angle, cohesion, and tensile strength) for all rock mass elements (except fault zones which are already at residual strength). Peak strengths were scaled linearly between the previously applied peak and residual values (Table 2) by a factor $\alpha$; for example, $c_{\text {red }}=c_{R}+\alpha\left(c-c_{R}\right)(\alpha=100 \%$ represents peak strength properties; $\alpha=0 \%$ represents residual strength).

Results shown in Figure 12 indicate that a weakened rock slope ( $\alpha=30 \%)$ experiences greater initial and subsequent damage during TM glacier cycles compared to a slope with moderate strength conditions 


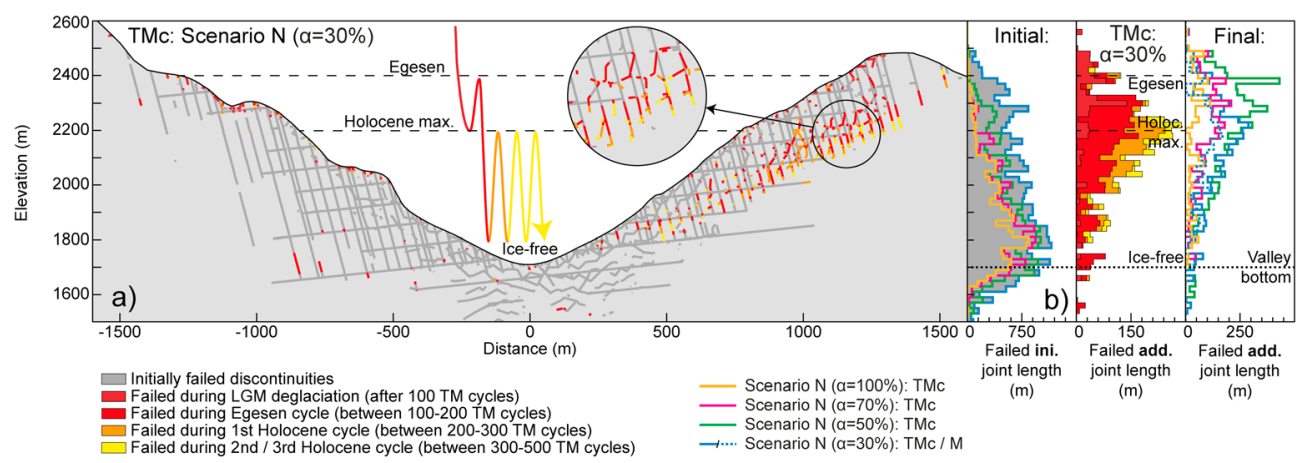

Figure 12. Influence of seasonal thermal cycles on rock slope damage for a weakened slope during repeat glacial cycles: (a) spatial and temporal distributions of damage induced by annual thermomechanical stress cycles (TMc) for model scenario $\mathrm{N}$ with $\alpha=30 \%$ in the cross section. (b) Damage elevations at initial conditions, additional damage with time for scenario N with $\alpha=30 \%$ induced by TMc, and final additional damage for scenario N with $\alpha=100 \%$ to $30 \%$ (in comparison to a purely mechanical (M) model with $\alpha=30 \%$ ) displayed as a histogram.

$(\alpha=100 \%)$. New damage occurs mostly on the eastern valley flank as propagation of preexisting steeply dipping discontinuities (Figure 12a). Failure of intact rock bridges (i.e., Voronoi contacts) connects existing failed joints generating a shear failure surface. Most damage occurs during first deglaciation and the first Holocene readvance. Figure $12 \mathrm{~b}$ displays histograms of damage elevation for strength reduction factors $\alpha=100 \%, 70 \%, 50 \%$, and $30 \%$ in model scenario N, showing similar damage patterns. Initial damage increases for weaker rock mass strength, and new damage is greatest for $\alpha=50 \%$. Although damage in a purely mechanical model under reduced strength conditions is significant, when TM effects are added, this damage increases by 5 to $12 \%$ (Figure 12b). Peak damage accumulation is located around the Holocene maximum ice elevation and decreases at lower elevations. Glacier fluctuations induce most damage around the elevation of the changing ice surface and a few hundred meters above (see Figure 11a). This damage pattern is enhanced under reduced rock strength conditions and strongest when including TM effects (Figure 12).

Maximum displacement in a purely mechanical model on the destabilized eastern flank $(\alpha=30 \%)$ is up to $\sim 0.5 \mathrm{~m}$ (Figure 13a). Including TM effects, displacements increase to $\sim 0.7 \mathrm{~m}$ and the extent of the unstable rock mass grows, becoming deeper and extending further toward the valley bottom (Figure 13b). In Figure 13d we compare horizontal displacement at observation point 1 within the unstable rock mass (see Figures 13a and 13b) for glacier scenarios $\mathrm{N}$ and $\mathrm{P}$ (Figure 13c). Irreversible displacement is superimposed on the elastic slope response to glacier loading and unloading (Grämiger et al., 2017). The timing of greatest displacement coincides with first glacier retreat in both scenarios, leading to initiation of a slope instability (Figure 13d). Displacement continues steadily during subsequent Holocene cycles in scenario N. Final displacement at point 1 is slightly larger when including Holocene cycles as compared to LGM deglaciation in scenario P. In Figure 13e we compare the additional displacement for models with $(\mathrm{N})$ and without $(\mathrm{P})$ a single Holocene cycle, each also benchmarked against a purely mechanical model. Under permanent ice-free conditions (P), seasonal TM cycles over 100 years result in an additional 1.0-cm displacement ( 0.1 mm per cycle) compared to the purely mechanical model. Additional displacement with a single Holocene cycle $(\mathrm{N})$ in a purely mechanical model is $\sim 3 \mathrm{~cm}$, while including TM effects this value increases to $\sim 5.3 \mathrm{~cm}$; enhanced $2.3 \mathrm{~cm}$ (or $\sim 0.2 \mathrm{~mm}$ per cycle).

Figure 14 shows shear displacement and the corresponding stress path for an example steeply dipping joint located in the midslope region at $~ 200-\mathrm{m}$ depth (location shown in Figure 13). Right-handed shear displacement along the joint occurs during LGM deglaciation (scenario P; Figure 14a). Shear dislocation during scenario $\mathrm{N}$ is similar for mechanical and TM models, although slip magnitudes are enhanced when including TM cycles. Most shearing occurs during first glacier retreat. Subsequent Holocene readvances promote further slip, while shearing during later retreat is smaller. During deglaciation, normal stresses decrease and shear stresses increase, and stress conditions move closer to the failure envelope (Figure 14b). The failure criterion restrains any further decrease in normal stress or increase in shear stress. Each subsequent Holocene cycle moves the stress state first away and then toward the failure envelope. Stresses reaching the failure 


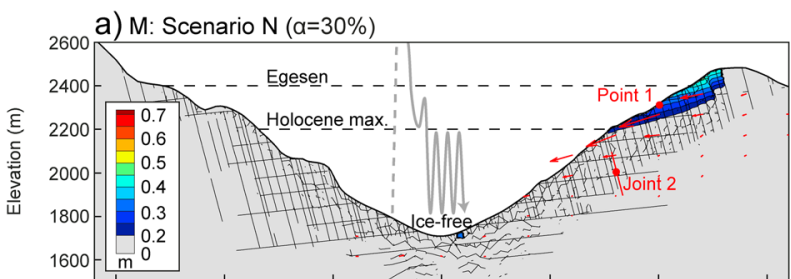

b) TMc: Scenario N ( $\alpha=30 \%)$

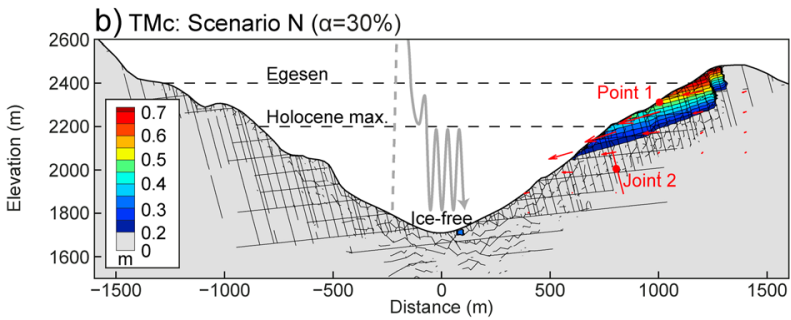

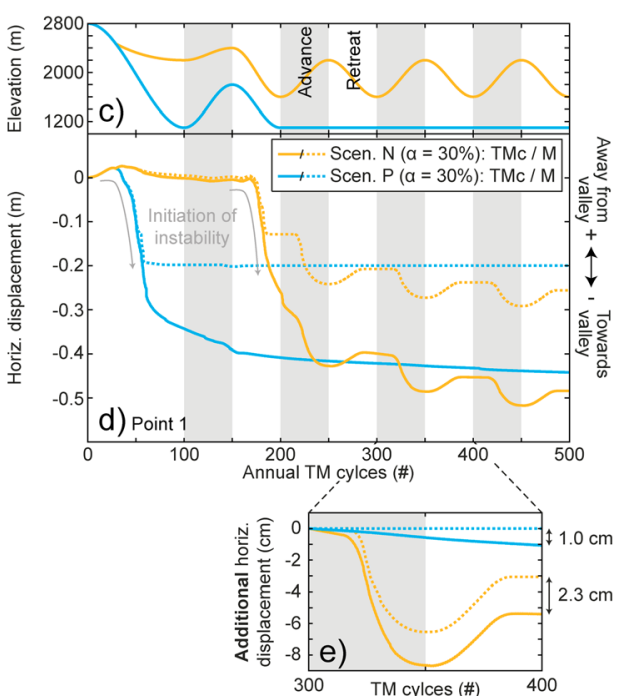

Figure 13. Displacement of a weakened rock slope illustrating development and evolution of landslide activity during repeat glacial cycles in concert with thermomechanical cycles: (a) maximum slope displacement and vectors (red arrows) for scenario $\mathrm{N}$ with $\alpha=30 \%$ for a complete glacial cycle (ice-free initialization until end of third Holocene cycle) for a purely mechanical (M) model and (b) with TM stress cycles (TMc) included. Location of observation point 1 and joint 2 shown. (c) Applied glacier scenarios $\mathrm{N}$ and P. (d) Absolute horizontal displacement $(\Delta x)$ for point 1 within the instability for glacier scenario $\mathrm{N}$ and $\mathrm{P}$ under reduced rock mass strength $(\alpha=30 \%)$, each comparing M and TMc. (e) Additional horizontal displacement ( $+\Delta x)$ for point 1 in scenarios without (blue) and with (orange) a single Holocene cycle (each showing TMc/M).

envelope generate irreversible slip (Figure 14a). Slip and accompanying stress redistribution are greater for TM models.

To further clarify details of the joint's stress path, we examine a single Holocene cycle in Figure 14c. Under icefree conditions, the observed joint is still critically stressed, with stresses at the failure envelope (inset c1). TM cycles invoke minor stress redistribution and slip. During glacier advance, the joint becomes more critically stressed as the ice surface reaches its elevation. TM stress cycles enhance glacially induced slip (Figure 14a). Once the glacier elevation rises above the joint, normal stresses increase and shear stresses decrease (Figure 14c); the joint becomes less critically stressed and shear dislocation ceases. The opposite occurs with retreat, as stress conditions again wander close to the failure envelope. Stresses reach the failure envelope when the glacier surface is around the elevation of the joint (inset c2). Stress redistribution is
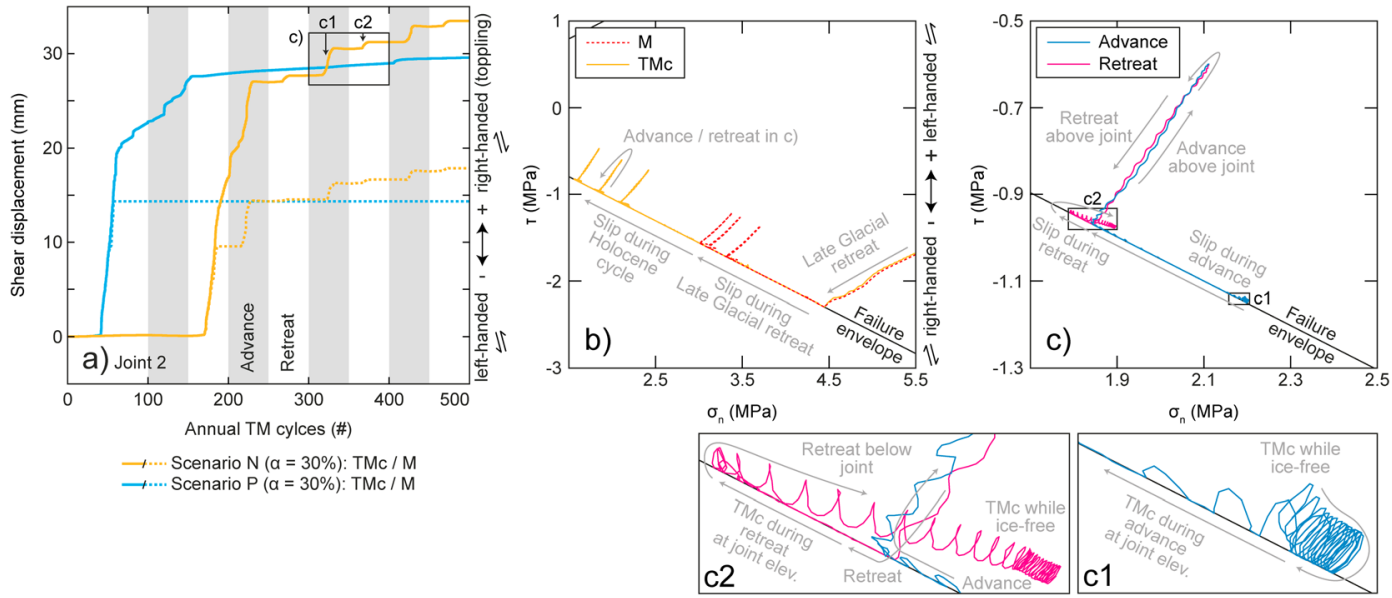

Figure 14. Shear displacement and corresponding stress path for observation joint 2 (see location in Figure 13) during glacial cycles: (a) shear displacement under scenarios $\mathrm{N}$ and $\mathrm{P}$ with $\alpha=30 \%$, each comparing $\mathrm{M}$ and thermomechanical stress cycles (TMc). (b) Stress path for scenario N comparing M and TMc (TM cycle 150 to 500). (c) Stress path for a single Holocene cycle (TM cycle 300 to 400 in scenario N) with details of times when the joint is most critically stressed during advance (c1) and retreat (c2). 
a) $M$ :

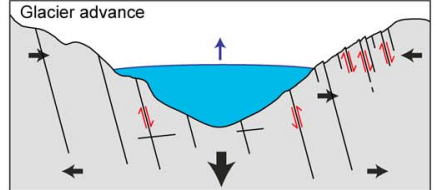

b) TMc:
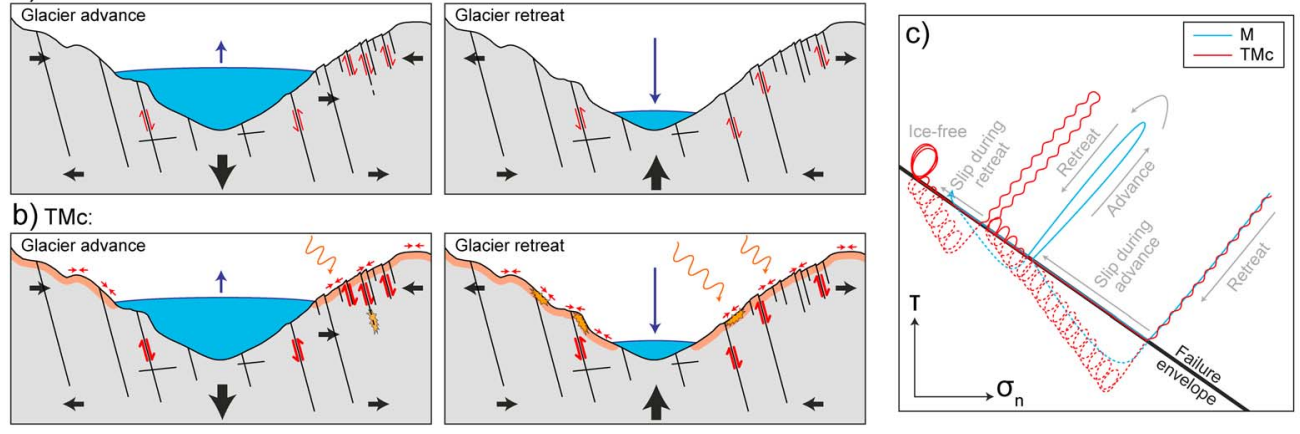

Figure 15. Conceptual sketch of mechanical and thermomechanical processes acting during a glacier cycle: (a) purely mechanical response during glacier advance and retreat. (b) TM response including annual temperature changes during glacier advance and retreat. (c) Conceptual stress path (shear stress versus normal stress) for a purely mechanical (M) model and a model including seasonal TM stress cycles. The dashed stress path shows the potential elastic stresses, while the solid line represents the plastic stress path limited by Mohr-Coulomb failure.

accompanied by slip and enhanced by TM stress cycles. After the glacier retreats below the joint elevation, the joint becomes less critically stressed, and stresses cycle away from the failure envelope. Stress conditions in an ice-free slope are critical, but without an additional driving mechanism pushing stresses toward the failure envelope, TM cycles create only minor slip (Figure 14a; scenario P). Each glacial cycle, advance and retreat alike, shifts joint stress conditions toward the failure envelope when the glacier elevation is near the joint elevation (Figure 14b). Compared to a purely mechanical model, resulting TM shear displacements are strongly enhanced (Figure 14a).

\section{Discussion}

\subsection{Thermally Induced Paraglacial Rock Slope Damage}

Our numerical simulations demonstrate the importance of including TM effects in conjunction with glacier loading cycles as a preparatory factor for paraglacial rock slope instabilities. Purely mechanical loading and unloading by a glacier results in downward and upward displacement, respectively, in subglacial bedrock (Figure 15a). During advances, the ice mass pushes the valley apart and toppling mode failure is activated on steeply dipping discontinuities above the glacier. Meanwhile, glacier fluctuations also affect bedrock thermal boundary conditions. While bedrock in contact with ice is nearly isothermal at $0{ }^{\circ} \mathrm{C}$, rock slopes above the glacier are exposed to solar radiation and air temperature changes with long-term, annual and daily variations (Figure 15b). Temperature changes on glacial time scales penetrate to depths of $\sim 100 \mathrm{~m}$, but our models show that TM strain reaches beyond these depths, affecting large areas of the slope and increasing rock mass damage during glacial cycles. Damage is further enhanced in the presence of annual temperature cycles (Figure 15b). While annual temperature changes are restricted to the upper $10 \mathrm{~m}$, TM strains reach deeper and represent an additional fatigue mechanism. While glacier loading and unloading predominantly affect the criticality of rock slopes, seasonal TM stress cycles act on critically stressed joints generating slip and additional damage. Glacier retreat shifts stress conditions along optimally oriented joints closer to the failure envelope, while TM stresses promote slip and stress redistribution during both retreat and advance (Figure 15c). Ongoing temperature change can lead to delayed damage by several thousand years (Figures 5a-5c). Long-term TM effects may thus contribute to time-dependent damage following deglaciation (cf. Prager et al., 2008; McColl, 2012), potentially explaining frequently observed lag times between deglaciation and the timing of slope failure (e.g., Ballantyne et al., 2014b; Ballantyne, Sandeman, et al., 2014a; McColl, 2012).

Other TM modeling studies support our results. Baroni et al. (2014) noted that TM effects resulting from longterm temperature changes during deglaciation can generate significant strains on adjacent slopes. This agrees with our finding that long-term TM effects have the potential to drive rock slope damage. Wegmann et al. (1998) investigated permafrost penetration as a consequence of glacier retreat as a factor leading to frost damage. Both studies showed how glacier change affects thermal boundary conditions in 

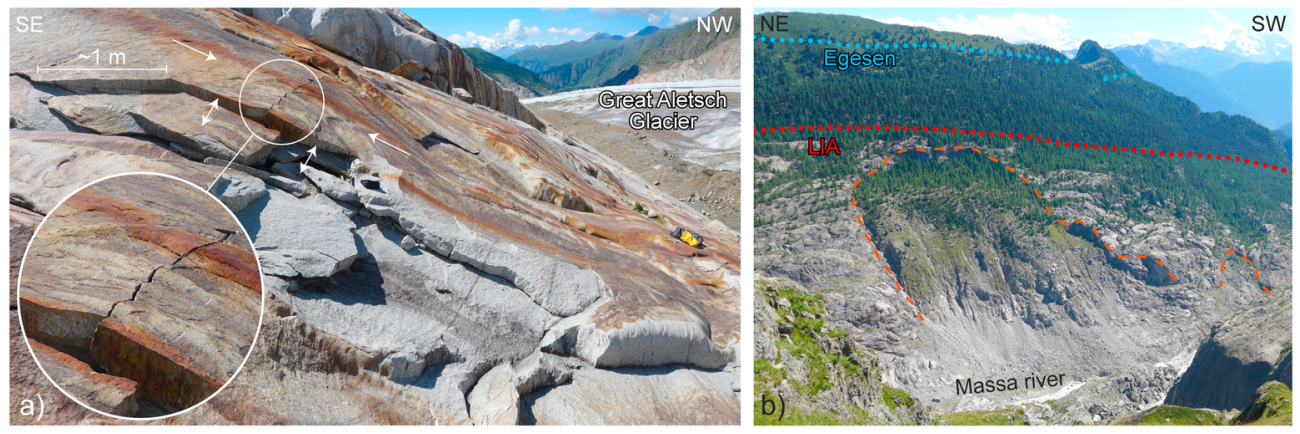

Figure 16. Example rock slope damage observed in the field at Aletsch (locations marked as asterisks in Figure 2): (a) surficial A-tent pop-up feature on the eastern valley flank near the margin of the Great Aletsch Glacier. (b) Silbers and landslide and smaller adjacent instability further south on the eastern flank of the Aletsch Valley.

adjacent rock walls on long time scales. On the other hand, Gischig et al. (2011a) demonstrated how seasonal TM cycles can drive progressive failure in a critically stressed, unstable rock slope. They showed the most damage occurs during an initial thermal-transient phase as the rock mass adapts to new boundary conditions. While this can occur after a slope failure exposes new rock faces to ambient air conditions (Gischig et al., 2011a, 2011b), the concept is more broadly applicable for rock walls exposed by glacier retreat. We combined annual TM cycles with glacier loading and demonstrated that induced displacements are strongly enhanced in the presence of TM stresses. While damage resulting from the initial thermal-transient equilibration was greatest during first deglaciation, repetition of this effect could not be observed in our models, although we suspect in reality that glacial erosion may be able to reset the shallow damaged zone. While seasonal TM cycles can act as a driving mechanism for creep of an existing unstable rock slope (Gischig et al., 2011b), we demonstrated their potential as preparatory factor for paraglacial rock slope failures. Rock walls in higher alpine areas that have remained ice-covered since the LGM may be especially prone to damage during first deglaciation, potentially resulting in increased rates of future rockfall in these regions as climate warming drives further glacier retreat.

Rock slope damage observed around the Aletsch Glacier further supports our modeling results. Shallow, new failure through intact rock can be found along the margin of the retreating Great Aletsch Glacier (Figure 16a). Although the specific driving force for this particular feature remains speculative, the recent failure indicates that local bedrock in the vicinity of retreating ice is critically stressed and that changes in boundary conditions generate fracturing, as similarly predicted by our models including annual TM cycles (Figure 10). Under reduced rock mass strength conditions, glacial cycles in our models generated sufficient damage to destabilize the slope and initiate landsliding (Figures 13a and 13b), while TM cycles enhanced this displacement. In the field, we observe rock slope instabilities with dimensions and kinematics closely resembling our model predictions (e.g., Figure 16b). TM effects together with fluctuating ice loads may contribute to preparing slopes for failure around the glacier terminus in the Aletsch region (Figure 2), although geological predisposition also plays an important role in local slope stability (Augustinus, 1995; Terzaghi, 1962). Most damage in our models occurred during first deglaciation and accompanying paraglacial thermal shock. Therefore, we propose that rock slopes higher in the Aletsch Valley within the Holocene minimum extent, currently covered by ice and likely never exposed since at least the LGM, may be more susceptible to damage during future deglaciation, especially at shallow depths. New damage may promote enhanced rates of rockfall in these regions.

\subsection{Model Limitations}

Our numerical modeling goes beyond the purely mechanical simulations presented by Grämiger et al. (2017) but has limitations. Long time scales of interest made it necessary for us to investigate long-term and seasonal thermal effects separately. These processes in reality act in concert and may augment one another, driving increased rates of rock slope damage. Furthermore, we had to reduce to number of annual TM cycles to permit timely modeling, whereas in reality the number of stress cycles that bedrock has experienced is an order of magnitude larger. Both limitations likely lead to underestimated induced damage. Evaluating the 
damage effect of hundreds of thousands of TM cycles, as an unglaciated hillslope above the LGM (e.g., nunataks) may have experienced, may additionally require a constitutive model accounting for fatigue. In our TM models, the amount of new damage accumulation decreases in an ice-free valley after deglaciation (scenario $P$ in Figure 9b). Incremental joint slip and stress redistribution are the principle driver of this subsequent damage, whereas fatigue behavior of rock might prolong this damage phase.

Furthermore, heat transport in our models occurs only by conduction, whereas in reality, heat advection by groundwater (Rybach \& Pfister, 1994) or air ventilation in cracks (Moore et al., 2011) can locally influence the geothermal gradient. Latent heat effects from melting ice or freezing water in pores/cracks were also not considered in our thermal models. While latent heat production or consumption may alter temperature penetration depths, saturation and the physical state of water in the void space influence heat transport; for example, frozen rock has an increased thermal conductivity (Wegmann, 1998). We also neglected secondary snow and ice cover after LGM ice retreat. Seasonal snow cover can reduce the amplitude of annual temperature cycles (Zhang, 2005) because snow insulates underlying bedrock from extreme winter temperatures (see Appendix A1), in turn affecting the amount of TM rock slope damage (Figure 9b). Similarly, local permanent ice or snow accumulations in the high mountain areas during the LGM may have insulated bedrock above the glacier reducing the large temperature increase during Late Glacial and Holocene warming implemented in our models (Figure 6c). Meanwhile, we assume isotropic thermal properties, even though foliation and geological structure may result in anisotropic behavior. However, despite these simplifications and assumptions, our modeled temperature field matches local observations in a borehole (Luethi \& Phillips, 2016), and the predicted amplitudes of seasonal surface displacements fit comfortably within the range of past field measurements (Bakun-Mazor et al., 2013; Gischig et al., 2011b).

We neglected secondary thermal effects, such as permafrost, which can create rock damage through segregation ice growth (Anderson, 1998; Duca et al., 2015; Hales \& Roering, 2005; Hales \& Roering, 2007; Krautblatter et al., 2013; Sanders et al., 2012; Wegmann \& Gudmundsson, 1999). While thermal strain depends only on temperature differences, permafrost depends on absolute temperatures. Glacier ice at the pressure melting point of $\sim 0{ }^{\circ} \mathrm{C}$ insulates subglacial bedrock from prevailing surface temperatures, which may be above or below freezing depending mostly on altitude. Therefore, ground temperature can either increase or decrease following deglaciation. In the latter case, available moisture in the rock can freeze and ice segregation drives damage. Field observation of active rock glaciers in our study area (Figure 2), as well as the measured temperature regime (see Appendix A1), limit the current extent of discontinuous permafrost to altitudes above $\sim 2,600 \mathrm{~m}$, covering the peaks of Bettmerhorn and Eggishorn. Decreased temperatures during the LGM or Egesen stadia may have lowered the permafrost altitude by a few hundred meters, although during that time most of the Aletsch Valley was covered by ice. We believe it is thus unlikely that permafrost effects were a major driving factor for rock slope damage in the lower Aletsch area, since these rock slopes were either covered by temperate glacial ice during the Late Glacial or mean temperatures were above freezing, for example, during the Holocene (Figures $5 \mathrm{~d}$ and $5 \mathrm{e}$ ). While permafrost may be less relevant for rock slope damage at lower altitudes, frost weathering is an important damage process for rock slopes experiencing glacier retreat at higher altitudes (Wegmann et al., 1998).

\section{Summary and Conclusions}

Bedrock in alpine valleys experiences strong temperature changes as glaciers advance and retreat in conjunction with long-term climatic transitions. Changes in the subsurface temperature field drive strain through TM coupling, and the resulting stresses can generate rock mass damage conditioning future slope instabilities. We investigated the spatial and temporal evolution of rock slope damage induced by glacier cycles and associated long-term and annual TM effects using detailed numerical models based on realistic site conditions at the Great Aletsch Glacier in Switzerland. Key outcomes of our study include the following:

1. Changing thermal boundary conditions during glacier retreat and advance, as well as ambient temperature trends over glacial/interglacial periods, alters the temperature field of paraglacial valley slopes to depths exceeding $100 \mathrm{~m}$. Thermal strain induced by long-term temperature changes promotes new rock fracturing in our numerical models. The timing of greatest damage occurs at the onset of the first Holocene ice readvance accompanying cooling of subglacial bedrock. In addition, a modest temperature increase of a few degrees over several thousand years after deglaciation is sufficient to induce significant 
new damage, even in the absence of additional glacier loading or unloading. Warming of bedrock after deglaciation also contributes to postglacial rebound.

2. Bedrock exposed for the first time to annual temperature cycles experiences strong TM stresses within the thermally active layer, generating a shallow damage front that migrates with the retreating glacier margin. Damage occurs as part of a transition we term paraglacial thermal shock, and the period of greatest damage is associated with first glacial retreat. Although damage is generally shallow, cyclic TM stresses propagate below the thermally active layer and create damage at greater depths. Future climate warming and glacier retreat will expose bedrock to annual TM cycles that have likely remained beneath ice since at least the LGM, potentially resulting in increased rates of rockfall in these regions.

3. Long-term TM effects in our models generate between 15\% and 19\% new damage (compared to the initial, inherited damage field), while a purely mechanical model driven by glacier loading cycles resulted in only $1 \%$ new damage. Annual TM cycles acting together with changing glacier load results in $10 \%$ to $11 \%$ new damage. Thermal effects (both long term and short term) in conjunction with glacier loading cycles thus represent a significant driver of paraglacial rock slope damage.

4. Glacier fluctuations acting on a slope with reduced rock mass strength produce considerable damage and displacement, initiating a slope instability in our models with comparable attributes as observed in the field at Aletsch. Annual TM cycles alone induced incremental damage and slope displacement, but acting together with glacier loading cycles TM stresses strongly enhanced the slope response during both ice retreat and advance.

5. Glacier retreat brings the stress state of joints in adjacent bedrock closer to the failure envelope, inducing slip. Initiation of annual TM cycles associated with deglaciation results in stress cycles on the MohrCoulomb failure envelope, creating additional slip as compared to a purely mechanical model. Therefore, TM effects must not be neglected when exploring stress changes associated with glacial cycles and rock slope damage. TM damage is an effective preparatory factor for paraglacial rock slope instabilities.

Ice makes a weak buttress for glaciated valley flanks, although it affects the stress field of the slope by adding confinement. Stress redistribution and postfailure strength reduction (i.e., slip-weakening), combined with long-term and annual TM effects accompanying glacier fluctuations are significantly ( 10 times) more effective in promoting damage than the purely mechanical effects of glacier loading and unloading alone. Deglaciation involves a complex, multiprocess transition of boundary conditions, including in addition to the mechanical load of ice, important changes in subsurface temperature that are capable of driving rock slope damage through TM coupling.

\section{Appendix A}

\section{A1. Ground Temperature Measurements at Aletsch}

Rock surface temperatures are required boundary conditions for our thermal model and depend mainly on air temperature and solar radiation (Anderson, 1998; Gruber et al., 2004). We measured local ground temperature in bedrock along valley profiles at different altitudes and aspect, compiling this information with other available data to describe the local temperature regime (Figure 2). The majority of temperature sensors were used to cover a large span of elevation on the eastern and western valley slopes, while a few loggers were placed close to the ice margin or within ice caves to measure the temperature transition in bedrock experiencing glacier retreat. The altitude of our sensors spanned from $\sim 2,000$ to 3,000 m, measuring on rock surfaces with mainly NW or SE aspect, representative of rock walls in our study area (see Figure 2 and Table A1). We used HOBO Pro v2 U23-003 loggers with two external temperature sensors with accuracy of $0.2{ }^{\circ} \mathrm{C}$. Data storage lasted around 1 year (at the measurement interval of $30 \mathrm{~min}$ ), and data collection was performed manually. The external temperature sensors were grouted into $\sim 5-\mathrm{cm}$ deep boreholes in the rock surface. At two positions (AT08 and AT09 in Figure 2) the second external temperature sensor was used to measure air temperature $\sim 20 \mathrm{~cm}$ above the ground using an aspirated solar shield.

The high alpine environment and remote locations of several loggers presented challenges. Loggers were destroyed by lightning (AT14), snow avalanche (AT07), and glacier movement (AT03 and AT04). Snow pressure during winter was difficult to anticipate, and therefore, cable breach of the external sensor was a problem at many locations (AT01). The redundancy of having two external sensors helped overcome this 
Table A1

Rock (and Air) Surface Temperature Measurements From This Study in the Aletsch Region With Values for Sine Function Fit

\begin{tabular}{llcrcccc} 
Name & \multicolumn{1}{c}{ Type } & $\begin{array}{c}\text { Elevation } \\
(\mathrm{m})\end{array}$ & $\begin{array}{c}\text { Azimuth } \\
\left({ }^{\circ}\right)\end{array}$ & $\begin{array}{c}\text { Dip } \\
\left({ }^{\circ}\right)\end{array}$ & $\begin{array}{c}\text { MA(G)T } \\
\left({ }^{\circ} \mathrm{C}\right)\end{array}$ & $\begin{array}{c}\text { Annual amplitude } \\
\left({ }^{\circ} \mathrm{C}\right)\end{array}$ & $\begin{array}{c}R^{2} \\
()\end{array}$ \\
\hline AT01 & Rock & 2,736 & 276 & 55 & - & - & - \\
AT02 & Rock & 2,350 & 265 & 64 & 5.18 & 10.65 & 0.78 \\
AT03 & Rock (ice margin) & 2,242 & - & - & - & - & - \\
AT04 & Rock (ice margin) & 2,251 & - & - & - & - & - \\
AT05 & Rock & 2,458 & 119 & 53 & 4.88 & 11.32 & 0.63 \\
AT06 & Rock & 2,699 & 125 & 57 & 5.02 & 8.61 & 0.61 \\
AT07 & Rock & 2,440 & 95 & 76 & - & - & - \\
AT08-1 & Air & 1,963 & - & - & 3.47 & 7.93 & 0.77 \\
AT08-2 & Rock & 1,963 & 128 & 16 & 5.94 & 9.51 & 0.84 \\
AT09-1 & Air & 1,966 & - & - & 2.49 & 7.21 & 0.76 \\
AT09-2 & Rock & 1,966 & 310 & 17 & 5.60 & 9.66 & 0.88 \\
AT10 & Rock (ice margin) & 1,938 & 50 & 56 & 2.71 & 7.27 & 0.88 \\
AT11 & Rock & 2,087 & 281 & 25 & 4.59 & 9.23 & 0.87 \\
AT12 & Rock & 2,374 & 300 & 31 & 3.42 & 10.21 & 0.78 \\
AT13 & Rock & 2,599 & 264 & 26 & 2.98 & 9.77 & 0.82 \\
AT14 & Rock & 2,800 & 258 & 60 & - & - & - \\
\hline
\end{tabular}

issue. Battery malfunction was also common in the cold weather conditions. Inaccessibility during winter allowed us to identify data gaps only during sporadic checks, resulting in data loss. Despite these difficulties, we were able to collect more than 3 years of temperature data for most of the sensors. Temperature time series data for sensors with satisfactory data coverage are shown in Figure A1. Applying a sine function fit to the daily average (filtering out times of snow or ice cover around $0{ }^{\circ} \mathrm{C}$ ) resulted in values for mean annual temperature (MAT) and annual amplitudes (Table A1). The beginning of the time series for sensor AT10 (Figure A1), located at the Aletsch Glacier margin, captured the transition of rock temperature during glacier retreat in summer 2012.

Figure A2 shows detailed analysis of rock surface temperature measurements collected in this study, complemented with MAGT measured at higher altitudes $(\sim 2,700-3,600 \mathrm{~m})$ in the Aletsch region by Wegmann (1998). MAGT varies with altitude although with large scatter (Figure A2a). Due to a lack of data, no clear dependency of MAGT or annual amplitude with the position of the Sun (azimuth and elevation angle of the Sun) with respect to the rock surface was apparent (Figures $A 2 b$ and $A 2 c$ ), although it would be expected (Gruber et al., 2004; Wegmann, 1998). However, we observe a clear pattern of the MAGT in relation to altitude and azimuth (Figure A2d). MAGT becomes warmer at lower elevations and southern exposures. The mean annual amplitude determined in our study is $9.58^{\circ} \mathrm{C}$ (Figure A2e). For our thermal models, it was necessary to define a relationship between temperature and altitude. Wegmann (1998) used different approximations of MAGT with altitude for northern and southern exposed rock walls at the nearby Jungfrau (Figure A2a). Moore et al. (2011) suggested using the same lapse rate for MAGT as for mean annual air temperature (MAAT), where ground temperatures are generally $\sim 1{ }^{\circ} \mathrm{C}$ warmer (Figure A2a). We analyzed regional air temperature data available from nearby weather stations (Table A2) and fitted sine functions through 1 year of daily temperature averages over several years (Table A2 and Figure A2f) to establish a regional MAAT fit with a lapse rate of $-0.0052{ }^{\circ} \mathrm{C} \mathrm{m}^{-1}(T(z)=12.2851-0.0052(z)$, where $z$ is meters; Figure A2g). Using the lapse rate from our regional MAAT analysis, we fit MAGT measured in this study complemented by data from Wegmann (1998), resulting in an approximation of $T(z)=15.3-0.005(z)$ (Figure A2a). MAGT is estimated to be $\sim 3{ }^{\circ} \mathrm{C}$ warmer than MAAT. The measured differences in MAT between air and rock at sites AT08 and AT09, respectively, are 2.5 to $3^{\circ} \mathrm{C}$ (Table $\mathrm{A} 1$ ), matching our approximation. Our final approximation of the transient ground temperature distribution as a function of time $(t)$ and elevation $(z)$ is thus (see also equation (1))

$$
T(t, z)=15.3-0.005(z)+10 \sin (2 \pi \mathrm{ft})
$$

where $t$ is in seconds, $z$ is meters, and $f$ is the 1-year annual frequency in $\mathrm{Hz}$. Equation (A1) results in a $0{ }^{\circ} \mathrm{C}$ isotherm for MAGT at 3,060 $\mathrm{m}$, while the regional MAAT fit reaches $0{ }^{\circ} \mathrm{C}$ isotherm at $2,363 \mathrm{~m}$ and $-1{ }^{\circ} \mathrm{C}$ at $2,555 \mathrm{~m}$ (discontinuous permafrost occurs where the MAAT is between -1 and $-6{ }^{\circ} \mathrm{C}$ ). 

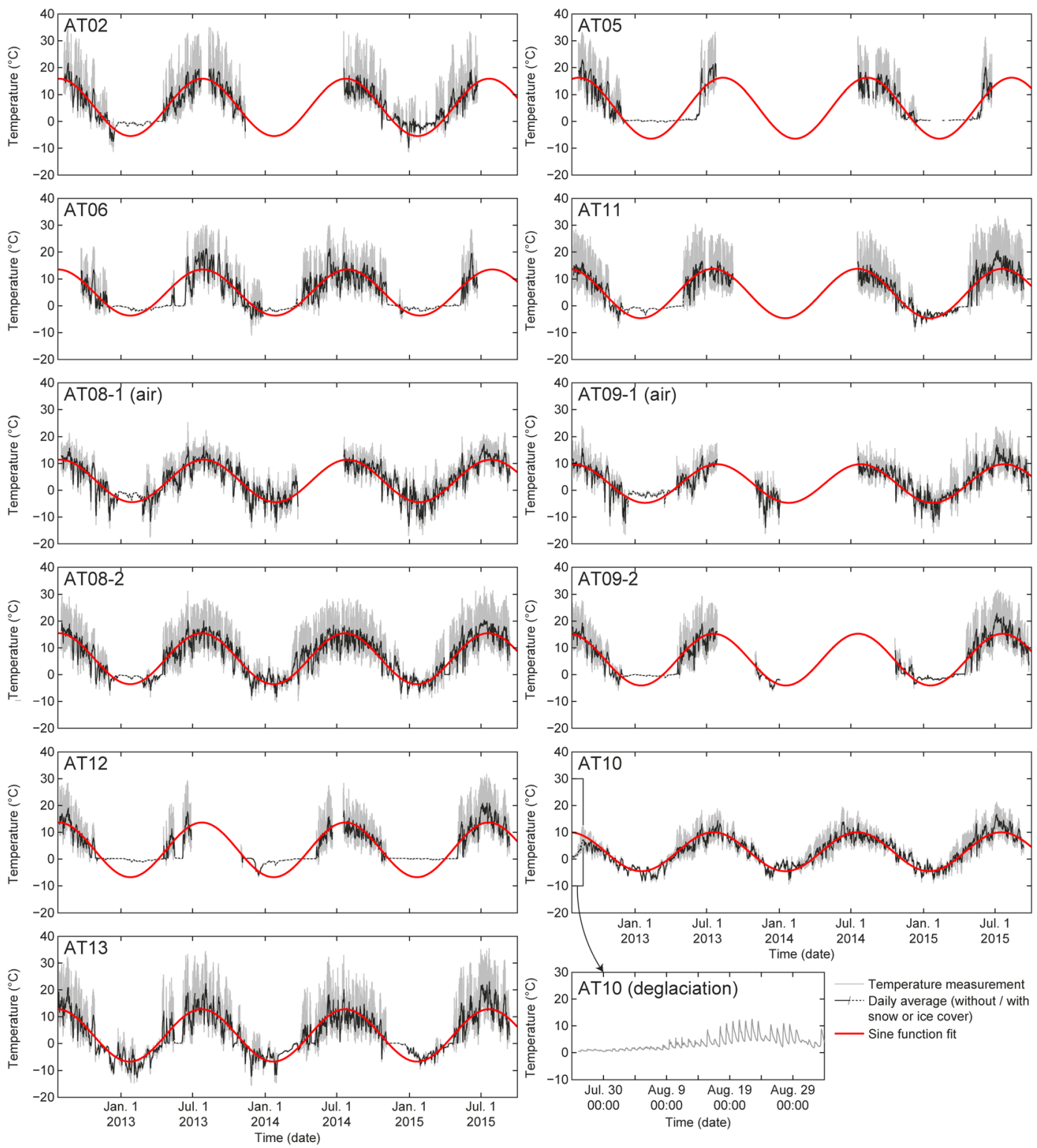

Figure A1. Time series of rock (and air) surface temperature measurements in the Aletsch region with daily average and sine-function fit (see Table A1). Enlargement of temperature transition in bedrock during present-day glacier retreat from near $0{ }^{\circ} \mathrm{C}$ to daily temperature cycles at sensor AT10.

\section{A2. Thermomechanical Coupling in the Model}

The transient temperature field is calculated in COMSOL by solving the heat transfer problem defined by thermal conduction in the medium and geothermal heat flux/ground surface temperature distribution as boundary conditions. The 1-D transient heat equation is defined through thermal diffusivity $D$ and given by

$$
\partial T / \partial t=D\left(\partial^{2} T / \partial x^{2}\right)
$$

where $x$ is depth. Temperature changes cause stress changes according to (Itasca, 2014)

$$
\Delta \sigma_{i j}=-\delta_{i j} 3 K \alpha \Delta T
$$

where $\Delta \sigma_{i j}$ is change in stress $i j, \delta_{i j}$ is Kronecker delta $\left(\delta_{i j}=1\right.$ for $i=j$ and 0 for $\left.i \neq j\right), K$ is the bulk modulus (under plane-strain conditions), $\alpha$ is the linear thermal expansion coefficient, and $\Delta T$ is temperature 

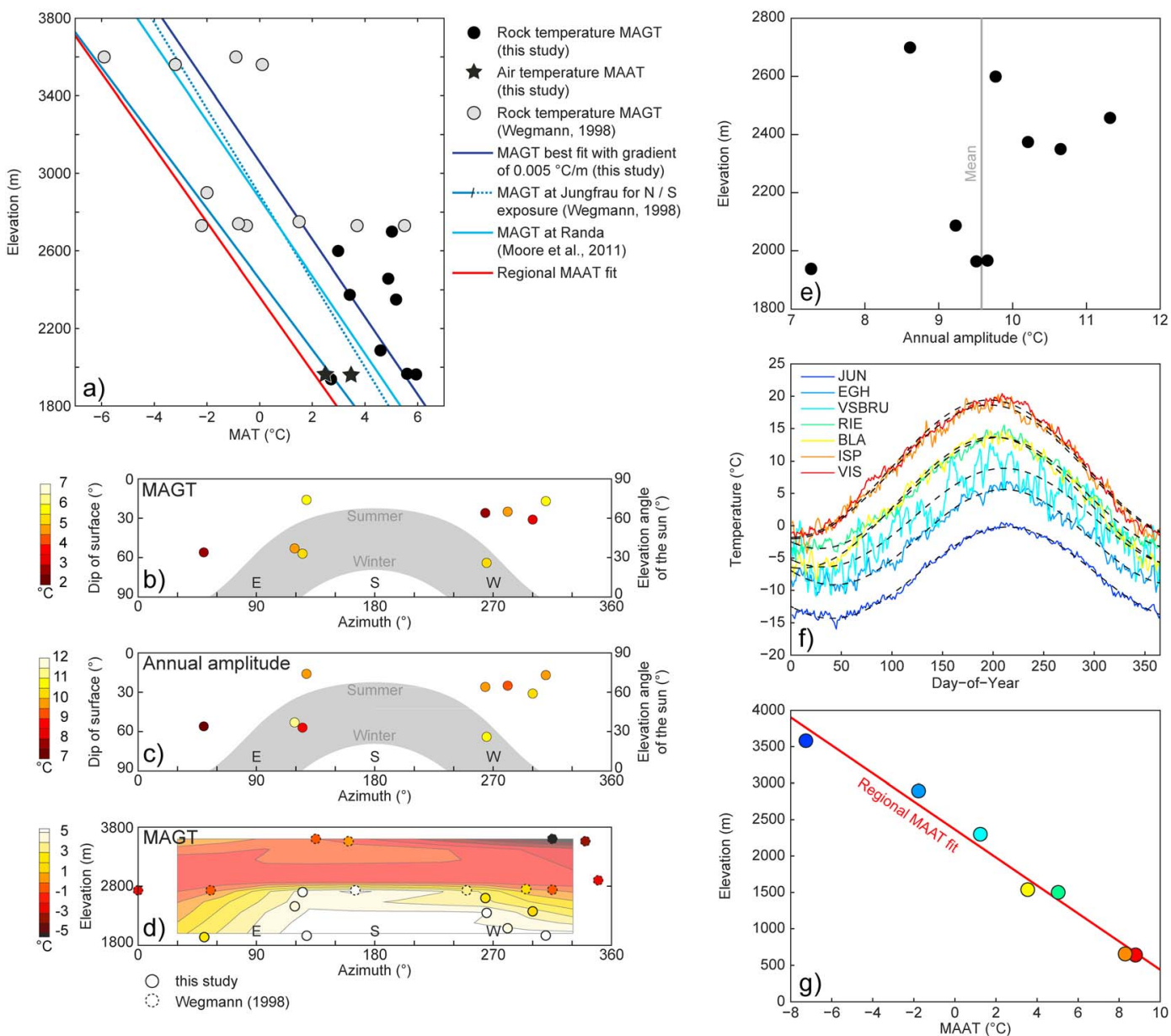

Figure A2. Analysis of rock and air temperature data from the Aletsch region: (a) MAGT and MAAT measurements (this study) complemented by MAGT from Wegmann (1998) versus altitude. Linear fit for MAGT and MAAT (this study) in comparison with past studies (Moore et al., 2011; Wegmann, 1998). (b) MAGT and (c) annual amplitude, respectively, versus position of the Sun (azimuth and elevation angle) with respect to the rock surface exposure. (d) MAGT (this study complemented with data from Wegmann, 1998) as a function of altitude and azimuth. (e) Mean annual amplitude versus altitude. (f) Available air temperature data from nearby weather stations, averaging daily temperatures over several years (Table A2) and fitting sine functions through 1 year. (g) Regional MAAT fit from available air temperature data (Table A2).

change. Temperature changes corresponding to each mechanical step in UDEC are used to assess thermal stresses and added to the prior stress state. Subsequently, the Mohr-Coulomb constitutive law $\left(\tau_{s}=\sigma_{n}\right.$ $\tan (\varphi)+c)$ including slip-weakening is applied, described in detail by Itasca (2014), simulating the decreasing frictional strength of discontinuities after failure and slip. This failure criterion is implemented in UDEC by reducing peak friction and cohesion instantaneously to a residual value, while tensile strength

Table A2

Air Temperature Data From Nearby Weather Stations (IDAweb by MeteoSchweiz) With Values for Sine Function Fit

\begin{tabular}{lcccrr}
\hline Name & Longitude/latitude & $\begin{array}{c}\text { Elevation } \\
(\mathrm{m})\end{array}$ & \multicolumn{1}{c}{$\begin{array}{c}\text { Time series } \\
(\text { Date })\end{array}$} & $\begin{array}{c}\text { MAAT } \\
\left({ }^{\circ} \mathrm{C}\right)\end{array}$ & $\begin{array}{c}\text { Annual amplitude } \\
\left({ }^{\circ} \mathrm{C}\right)\end{array}$ \\
\hline JUN; Jungfraujoch & $7^{\circ} 59^{\prime} / 46^{\circ} 33^{\prime}$ & 3,580 & January 1933 to August 2015 & -7.26 & 7.04 \\
EGH; Eggishorn & $8^{\circ} 06^{\prime} / 46^{\circ} 26^{\prime}$ & 2,893 & October 1993 to August 2015 & -1.77 & 0.99 \\
VSBRU; Bruchji & $7^{\circ} 58^{\prime} / 46^{\circ} 23^{\prime}$ & 2,300 & September 2012 to August 2015 & 1.25 & 7.37 \\
RIE; Ried & $7^{\circ} 48^{\prime} / 46^{\circ} 25^{\prime}$ & 1,500 & January 1974 to February 1999 & 5.03 & 0.97 \\
BLA; Blatten & $7^{\circ} 49^{\prime} / 46^{\circ} 25^{\prime}$ & 1,538 & March 2001 to August 2015 & 3.55 & 8.56 \\
ISP; Visp & $7^{\circ} 53^{\prime} / 46^{\circ} 17^{\prime}$ & 655 & July 1959 to December 1970 & 8.30 & 10.12 \\
VIS; Visp & $7^{\circ} 51^{\prime} / 46^{\circ} 18^{\prime}$ & 639 & December 1979 to August 2015 & 8.80 & 10.34 \\
\hline
\end{tabular}


drops to zero (see Table 2), when joint stresses exceed either the peak tensile or shear strength. Excess stress leads to joint slip, followed by stress relief and stress redistribution. Joint stresses result in displacement normal to and along the discontinuity as described by the Coulomb slip model (Itasca, 2014). In the normal direction, joint displacement in the model is assumed to be linear and governed by the normal stiffness $k_{n}$ (Table 2) such that

$$
\Delta \sigma_{n}=-k_{n} \Delta u_{n}
$$

where $\Delta \sigma_{n}$ is the normal stress increment and $\Delta u_{n}$ is the normal displacement increment inducing joint opening or closure. In shear, if shear strength is not exceeded, the joint response is controlled by the shear stiffness $k_{s}$ (Table 2):

$$
\Delta \tau_{s}=-k_{s} \Delta u_{s}^{e}
$$

where $\Delta u_{s}^{e}$ is the elastic component of the incremental shear displacement. In addition, if shear strength is exceeded, joint dilation may occur at the onset of slip (inelastic joint displacement) and specified by the dilation angle (Table 2).

\section{Acknowledgments}

This project was funded by the Swiss National Science Foundation (projects 135184 and 146593). Data used in this study can be found in the citations listed in the references. Data output is included in the tables and figures; raw temperature data are available as an electronic supplement. Special thanks to Johnny Sanders and Reto Seifert for field and technical assistance. Constructive comments from Neal Iverson and three anonymous reviewers, as well as associate editor David L. Egholm, are greatly appreciated and helped improve this manuscript.

\section{References}

Alley, R. B., Meese, D. A., Shuman, C. A., Gow, A. J., Taylor, K. C., Grootes, P. M., et al. (1993). Abrupt increase in Greenland snow accumulation at the end of the Younger Dryas event. Nature, 362(6420), 527-529. https://doi.org/10.1038/362527a0

Anderson, R. S. (1998). Near-surface thermal profiles in alpine bedrock: Implications for the frost weathering of rock. Arctic and Alpine Research, 30(4), 362-372. https://doi.org/10.2307/1552008

Anderson, R. S., \& Anderson, S. P. (2010). Geomorphology: The mechanics and chemistry of landscapes. Cambridge: Cambridge University Press. $340 \mathrm{pp}$

Augustinus, P. C. (1995). Glacial valley cross-profile development: The influence of in situ rock stress and rock mass strength, with examples from the Southern Alps, New Zealand. Geomorphology, 14(2), 87-97. https://doi.org/10.1016/0169-555x(95)00050-x

Bakun-Mazor, D., Hatzor, Y. H., Glaser, S. D., \& Carlos Santamarina, J. (2013). Thermally vs. seismically induced block displacements in Masada rock slopes. International Journal of Rock Mechanics and Mining Sciences, 61, 196-211. https://doi.org/10.1016/j.ijrmms.2013.03.005

Ballantyne, C. K. (2002). Paraglacial geomorphology. Quaternary Science Reviews, 21(18-19), 1935-2017. https://doi.org/10.1016/s02773791(02)00005-7

Ballantyne, C. K., Sandeman, G. F., Stone, J. O., \& Wilson, P. (2014a). Rock-slope failure following late Pleistocene deglaciation on tectonically stable mountainous terrain. Quaternary Science Reviews, 86, 144-157. https://doi.org/10.1016/j.quascirev.2013.12.021

Ballantyne, C. K., \& Stone, J. O. (2013). Timing and periodicity of paraglacial rock-slope failures in the Scottish Highlands. Geomorphology, 186, 150-161. https://doi.org/10.1016/j.geomorph.2012.12.030

Ballantyne, C. K., Wilson, P., Gheorghiu, D., \& Rodés, À. (2014b). Enhanced rock-slope failure following ice-sheet deglaciation: Timing and causes. Earth Surface Processes and Landforms, 39(7), 900-913. https://doi.org/10.1002/esp.3495

Baroni, C., Martino, S., Salvatore, M. C., Scarascia Mugnozza, G., \& Schilirò, L. (2014). Thermomechanical stress-strain numerical modelling of deglaciation since the Last Glacial Maximum in the Adamello Group (Rhaetian Alps, Italy). Geomorphology, 226, 278-299. https://doi.org/ 10.1016/j.geomorph.2014.08.013

Blunier, T., \& Brook, E. J. (2001). Timing of millennial-scale climate change in Antarctica and Greenland during the Last Glacial Period. Science, 291(5501), 109-112. https://doi.org/10.1126/science.291.5501.109

Boulton, G., Chan, T., Christiansson, R., Ericsson, L. O., Hartikainen, J., Jensen, M. R., et al. (2004). In S. Ove (Ed.), Thermo-hydro-mechanical (T-HM) impacts of glaciation and implications for deep geologic disposal of nuclear waste, Elsevier geo-engineering book series, edited by, (pp. 299-304). Elsevier. doi:https://doi.org/10.1016/S1571-9960(04)80057-0

Bovis, M. J. (1990). Rock-slope deformation at Affliction Creek, southern Coast Mountains, British Columbia. Canadian Journal of Earth Sciences, 27(2), 243-254. https://doi.org/10.1139/e90-024

Collins, B. D., \& Stock, G. M. (2016). Rockfall triggering by cyclic thermal stressing of exfoliation fractures. Nature Geoscience, advance online publication, 9(5), 395-400. https://doi.org/10.1038/ngeo2686

COMSOL Multiphysics (2015). Reference manual, version 5.1, COMSOL, Inc, www.comsol.com

Cossart, E., Braucher, R., Fort, M., Bourlès, D. L., \& Carcaillet, J. (2008). Slope instability in relation to glacial debuttressing in alpine areas (upper durance catchment, southeastern France): Evidence from field data and 10Be cosmic ray exposure ages. Geomorphology, 95(1-2), 3-26. https://doi.org/10.1016/j.geomorph.2006.12.022

Cundall, P. A., \& Hart, R. D. (1992). Numerical modelling of discontinua. Engineering Computations, 9(2), 101-113. https://doi.org/10.1108/ eb023851

Dahl-Jensen, D., Albert, M. R., Aldahan, A., Azuma, N., Balslev-Clausen, D., Baumgartner, M., et al. (2013). Eemian interglacial reconstructed from a Greenland folded ice core. Nature, 493(7433), 489-494. https://doi.org/10.1038/nature11789

Darnault, R., Rolland, Y., Braucher, R., Bourlès, D., Revel, M., Sanchez, G., \& et al. (2012). Timing of the last deglaciation revealed by receding glaciers at the Alpine-scale: Impact on mountain geomorphology. Quaternary Science Reviews, 31, 127-142. https://doi.org/10.1016/j. quascirev.2011.10.019

Davis, B. A. S., Brewer, S., Stevenson, A. C., \& Guiot, J. (2003). The temperature of Europe during the Holocene reconstructed from pollen data. Quaternary Science Reviews, 22(15-17), 1701-1716. https://doi.org/10.1016/S0277-3791(03)00173-2

Draebing, D., Krautblatter, M., \& Dikau, R. (2014). Interaction of thermal and mechanical processes in steep permafrost rock walls: A conceptual approach. Geomorphology, 226, 226-235. https://doi.org/10.1016/j.geomorph.2014.08.009

Duca, S., Alonso, E. E., \& Scavia, C. (2015). A permafrost test on intact gneiss rock. International Journal of Rock Mechanics and Mining Sciences, 77, 142-151. https://doi.org/10.1016/j.jirmms.2015.02.003 
Eberhardt, E., Stead, D., \& Coggan, J. S. (2004). Numerical analysis of initiation and progressive failure in natural rock slopes-The 1991 Randa rockslide. International Journal of Rock Mechanics and Mining Sciences, 41(1), 69-87. https://doi.org/10.1016/s1365-1609(03)00076-5

Eppelbaum, L., Kutasov, I., \& Pilchin, A. (2014). Thermal properties of rocks and density of fluids. In Applied geothermics, edited, (pp. 99-149). Berlin Heidelberg: Springer. doi:https://doi.org/10.1007/978-3-642-34023-9_2

Eppes, M. C., Magi, B., Hallet, B., Delmelle, E., Mackenzie-Helnwein, P., Warren, K., \& et al. (2016). Deciphering the role of solar-induced thermal stresses in rock weathering. Geological Society of America Bulletin, 128(9-10), 1315-1338. https://doi.org/10.1130/b31422.1

Evans, S. G., \& Clague, J. J. (1994). Recent climatic change and catastrophic geomorphic processes in mountain environments. Geomorphology, 10(1-4), 107-128. https://doi.org/10.1016/0169-555x(94)90011-6

Faillettaz, J., Sornette, D., \& Funk, M. (2010). Gravity-driven instabilities: Interplay between state- and velocity-dependent frictional sliding and stress corrosion damage cracking. Journal of Geophysical Research, 115, B03409. https://doi.org/10.1029/2009jb006512

Gischig, V., Preisig, G., \& Eberhardt, E. (2015). Numerical investigation of seismically induced rock mass fatigue as a mechanism contributing to the progressive failure of deep-seated landslides. Rock Mechanics and Rock Engineering, 49(6), 2457-2478. https://doi.org/10.1007/ s00603-015-0821-z

Gischig, V. S., Moore, J. R., Evans, K. F., Amann, F., \& Loew, S. (2011a). Thermomechanical forcing of deep rock slope deformation: 1. Conceptual study of a simplified slope. Journal of Geophysical Research, 116, F04010. https://doi.org/10.1029/2011jf002006

Gischig, V. S., Moore, J. R., Evans, K. F., Amann, F., \& Loew, S. (2011b). Thermomechanical forcing of deep rock slope deformation: 2. The Randa rock slope instability. Journal of Geophysical Research, 116, F04011. https://doi.org/10.1029/2011jf002007

Grämiger, L. M., Moore, J. R., Gischig, V. S., Ivy-Ochs, S., \& Loew, S. (2017). Beyond debuttressing: Mechanics of paraglacial rock slope damage during repeat glacial cycles. Journal of Geophysical Research: Earth Surface, 122, 1004-1036. https://doi.org/10.1002/2016JF003967

Gruber, S., Hoelzle, M., \& Haeberli, W. (2004). Rock-wall temperatures in the Alps: Modelling their topographic distribution and regional differences. Permafrost and Periglacial Processes, 15(3), 299-307. https://doi.org/10.1002/ppp.501

Gunzburger, Y., Merrien-Soukatchoff, V., \& Guglielmi, Y. (2005). Influence of daily surface temperature fluctuations on rock slope stability: Case study of the Rochers de Valabres slope (France). International Journal of Rock Mechanics and Mining Sciences, 42(3), 331-349. https:// doi.org/10.1016/j.ijrmms.2004.11.003

Hales, T. C., \& Roering, J. J. (2005). Climate-controlled variations in scree production, Southern Alps, New Zealand. Geology, 33(9), 701-704. https://doi.org/10.1130/g21528.1

Hales, T. C., \& Roering, J. J. (2007). Climatic controls on frost cracking and implications for the evolution of bedrock landscapes. Journal of Geophysical Research, 112, F02033. https://doi.org/10.1029/2006jf000616

Hall, K. (1999). The role of thermal stress fatigue in the breakdown of rock in cold regions. Geomorphology, 31(1-4), 47-63. https://doi.org/ $10.1016 / \mathrm{S} 0169-555 \mathrm{X}(99) 00072-0$

Hall, K., \& André, M.-F. (2001). New insights into rock weathering from high-frequency rock temperature data: An Antarctic study of weathering by thermal stress. Geomorphology, 41(1), 23-35. https://doi.org/10.1016/S0169-555X(01)00101-5

Hansmann, J., Loew, S., \& Evans, K. (2012). Reversible rock-slope deformations caused by cyclic water-table fluctuations in mountain slopes of the Central Alps, Switzerland. Hydrogeology Journal, 20(1), 73-91. https://doi.org/10.1007/s10040-011-0801-7

Harrison, J. C., \& Herbst, K. (1977). Thermoelastic strains and tilts revisited. Geophysical Research Letters, 4(11), 535-537. https://doi.org/ 10.1029/GL004i011p00535

Harrison, W. D. (1975). Temperature measurements in a temperate glacier. Journal of Glaciology, 14(70), 23-30. https://doi.org/10.3198/ 1975JoG14-70-23-30

Hasler, A., Gruber, S., \& Beutel, J. (2012). Kinematics of steep bedrock permafrost. Journal of Geophysical Research, 117, F01016. https://doi. org/10.1029/2011jf001981

Heiri, O., Koinig, K. A., Spötl, C., Barrett, S., Brauer, A., Drescher-Schneider, R., et al. (2014). Palaeoclimate records 60-8 ka in the Austrian and Swiss Alps and their forelands. Quaternary Science Reviews, 106, 186-205. https://doi.org/10.1016/j.quascirev.2014.05.021

Holzhauser, H., Magny, M., \& Zumbühl, H. J. (2005). Glacier and lake-level variations in west-central Europe over the last 3500 years. The Holocene, 15(6), 789-801. https://doi.org/10.1191/0959683605hl853ra

Itasca (2014). UDEC - Universal distinct element code, Version 6.0, User's Manual, Itasca Consulting Group, Inc., Minneapolis.

Ivy-Ochs, S. (2015). Glacier variations in the European Alps at the end of the last glaciation. Cuadernos de Investigacion Geografica, 41(2), 295-315. https://doi.org/10.18172/cig.2750

Ivy-Ochs, S., Kerschner, H., Maisch, M., Christl, M., Kubik, P. W., \& Schlüchter, C. (2009). Latest Pleistocene and Holocene glacier variations in the European Alps. Quaternary Science Reviews, 28(21-22), 2137-2149. https://doi.org/10.1016/j.quascirev.2009.03.009

Ivy-Ochs, S., Kerschner, H., Reuther, A., Preusser, F., Heine, K., Maisch, M., et al. (2008). Chronology of the last glacial cycle in the European Alps. Journal of Quaternary Science, 23(6-7), 559-573. https://doi.org/10.1002/jqs.1202

Jaboyedoff, M., Baillifard, F., Bardou, E., \& Girod, F. (2004). The effect of weathering on Alpine rock instability. Quarterly Journal of Engineering Geology and Hydrogeology, 37(2), 95-103. https://doi.org/10.1144/1470-9236/03-046

Jaboyedoff, M., Derron, M.-H., Jakubowski, J., Oppikofer, T., \& Pedrazzini, A. (2012). The 2006 Eiger rockslide, European Alps, (1st ed.). Cambridge: Cambridge University Press.

Joerin, U. E., Stocker, T. F., \& Schlüchter, C. (2006). Multicentury glacier fluctuations in the Swiss Alps during the Holocene. The Holocene, 16(5), 697-704. https://doi.org/10.1191/0959683606hl964rp

Jouvet, G., Huss, M., Funk, M., \& Blatter, H. (2011). Modelling the retreat of Grosser Aletschgletscher, Switzerland, in a changing climate. Journal of Glaciology, 57(206), 1033-1045. https://doi.org/10.3189/002214311798843359

Kääb, A. (2002). Monitoring high-mountain terrain deformation from repeated air- and spaceborne optical data: Examples using digital aerial imagery and ASTER data. ISPRS Journal of Photogrammetry and Remote Sensing, 57(1-2), 39-52. https://doi.org/10.1016/s09242716(02)00114-4

Kastrup, U., Zoback, M. L., Deichmann, N., Evans, K. F., Giardini, D., \& Michael, A. J. (2004). Stress field variations in the Swiss Alps and the northern Alpine foreland derived from inversion of fault plane solutions. Journal of Geophysical Research, 109, B01402. https://doi.org/ $10.1029 / 2003$ jb002550

Kelly, M. A., Kubik, P. W., Von Blanckenburg, F., \& Schlüchter, C. (2004). Surface exposure dating of the Great Aletsch Glacier Egesen moraine system, western Swiss Alps, using the cosmogenic nuclide 10Be. Journal of Quaternary Science, 19(5), 431-441. https://doi.org/10.1002/ jqs.854

Keusen, H. R., \& Amiguet, J. L. (1987). Die Neubauten auf dem Jungfraujoch. Geologie, Felseigenschaften, Permafrost. Schweizer Ingenieur und Architekt, 30-31, 17-18.

Kos, A., Amann, F., Strozzi, T., Delaloye, R., von Ruette, J., \& Springman, S. (2016). Contemporary glacier retreat triggers a rapid landslide response, Great Aletsch Glacier, Switzerland. Geophysical Research Letters, 43, 12,466-412,474. https://doi.org/10.1002/2016GL071708 
Krautblatter, M., Funk, D., \& Günzel, F. K. (2013). Why permafrost rocks become unstable: A rock-ice-mechanical model in time and space. Earth Surface Processes and Landforms, 38(8), 876-887. https://doi.org/10.1002/esp.3374

Leith, K., Moore, J. R., Amann, F., \& Loew, S. (2014). In situ stress control on microcrack generation and macroscopic extensional fracture in exhuming bedrock. Journal of Geophysical Research: Solid Earth, 119, 594-615. https://doi.org/10.1002/2012jb009801

Loew, S., Gischig, V. S., Glueer, F., Seifert, R., \& Moore, J. R. (2017). Multidisciplinary monitoring of progressive failure processes in brittle rock slopes. In X.-T. Feng, \& J. A. Hudson (Eds.), Rock mechanics and engineering, (chap. 20, pp. 629-662). Boca Raton: CRC Press/Balkema Taylor and Francis Group.

Lorig, L. J., \& Cundall, P. A. (1989). Modeling of reinforced concrete using the distinct element method. In S. P. Shah, \& S. E. Swartz (Eds.), Fracture of concrete and rock, edited by, (pp. 276-287). New York: Springer. doi:https://doi.org/10.1007/978-1-4612-3578-1_28

Luethi, R., \& Phillips, M. (2016). Challenges and solutions for long-term permafrost borehole temperature monitoring and data interpretation Geographica Helvetica, 71(2), 121-131. https://doi.org/10.5194/gh-71-121-2016

Maisch, M., Wipf, A., Denneler, B., Battaglia, J., \& Benz, C. (1999). Die Gletscher der Schweizer Alpen: Gletscherhochstand 1850, Aktuelle Vergletscherung, Gletscherschwund-Szenarien. Schlussbericht NFP 31, vdf Hochschulverlag.

McColl, S. T. (2012). Paraglacial rock-slope stability. Geomorphology, 153-154, 1-16. https://doi.org/10.1016/j.geomorph.2012.02.015

McColl, S. T., \& Davies, T. R. H. (2013). Large ice-contact slope movements: Glacial buttressing, deformation and erosion. Earth Surface Processes and Landforms, 38(10), 1102-1115. https://doi.org/10.1002/esp.3346

McColl, S. T., Davies, T. R. H., \& McSaveney, M. J. (2010). Glacier retreat and rock-slope stability: Debunking debuttressing. In G. Active (Ed.), 11th Congress of the International Association for Engineering Geology and the Environment, edited by, (pp. 467-474). Auckland, New Zealand: CRC Press.

McColl, S. T., Davies, T. R. H., \& McSaveney, M. J. (2012). The effect of glaciation on the intensity of seismic ground motion. Earth Surface Processes and Landforms, 37(12), 1290-1301. https://doi.org/10.1002/esp.3251

Moore, J. R., Gischig, V., Katterbach, M., \& Loew, S. (2011). Air circulation in deep fractures and the temperature field of an alpine rock slope. Earth Surface Processes and Landforms, 36(15), 1985-1996. https://doi.org/10.1002/esp.2217

Nicolussi, K., \& Schlüchter, C. (2012). The 8.2 ka event-Calendar-dated glacier response in the Alps. Geology, 40(9), 819-822. https://doi.org/ 10.1130/g32406.1

Prager, C., Zangerl, C., Patzelt, G., \& Brandner, R. (2008). Age distribution of fossil landslides in the Tyrol (Austria) and its surrounding areas. Natural Hazards and Earth System Sciences, 8(2), 377-407. https://doi.org/10.5194/nhess-8-377-2008

Preisig, G., Eberhardt, E., Smithyman, M., Preh, A., \& Bonzanigo, L. (2016). Hydromechanical rock mass fatigue in deep-seated landslides accompanying seasonal variations in pore pressures. Rock Mechanics and Rock Engineering, 49(6), 2333-2351. https://doi.org/10.1007/ s00603-016-0912-5

Röthlisberger, F., \& Schneebeli, W. (1979). Genesis of lateral moraine complexes, demonstrated by fossil soils and trunks: Indicators of postglacial climatic fluctuations. In C. Schlüchter (Ed.), Moraines and varves; Origin, genesis, classification, edited by, (pp. 387-419). Rotterdam, Netherlands: A.A. Balkema.

Rybach, L., \& Pfister, M. (1994). Temperature predictions and predictive temperatures in deep tunnels. Rock Mechanics and Rock Engineering 27(2), 77-88. https://doi.org/10.1007/bf01020206

Sanders, J. W., Cuffey, K. M., Moore, J. R., MacGregor, K. R., \& Kavanaugh, J. L. (2012). Periglacial weathering and headwall erosion in cirque glacier bergschrunds. Geology, 40(9), 779-782. https://doi.org/10.1130/g33330.1

Schimmelpfennig, I., Schaefer, J. M., Akçar, N., Ivy-Ochs, S., Finkel, R. C., \& Schlüchter, C. (2012). Holocene glacier culminations in the Western Alps and their hemispheric relevance. Geology, 40(10), 891-894. https://doi.org/10.1130/g33169.1

Schindelwig, I., Akçar, N., Kubik, P. W., \& Schlüchter, C. (2012). Lateglacial and early Holocene dynamics of adjacent valley glaciers in the Western Swiss Alps. Journal of Quaternary Science, 27(1), 114-124. https://doi.org/10.1002/jqs.1523

Schulson, E. M. (1990). The brittle compressive fracture of ice. Acta Metallurgica et Materialia, 38(10), 1963-1976. https://doi.org/10.1016/ 0956-7151(90)90308-4

Slaymaker, O. (2009). Proglacial, periglacial or paraglacial? Geological Society, London, Special Publications, 320(1), 71-84. https://doi.org/ $10.1144 / \mathrm{sp} 320.6$

Steck, A. (2011). 1269 Aletschgletscher mit Teil von 1249 Finsteraarhorn, Geologischer Atlas der Schweiz 1:25000.

Strozzi, T., Delaloye, R., Kääb, A., Ambrosi, C., Perruchoud, E., \& Wegmüller, U. (2010). Combined observations of rock mass movements using satellite SAR interferometry, differential GPS, airborne digital photogrammetry, and airborne photography interpretation. Journal of Geophysical Research, 115, F01014. https://doi.org/10.1029/2009jf001311

Terzaghi, K. (1962). Stability of steep slopes on hard unweathered rock. Géotechnique, 12(4), 251-270. https://doi.org/10.1680/ geot.1962.12.4.251

Vinther, B. M., Buchardt, S. L., Clausen, H. B., Dahl-Jensen, D., Johnsen, S. J., Fisher, D. A., et al. (2009). Holocene thinning of the Greenland ice sheet. Nature, 461(7262), 385-388. https://doi.org/10.1038/nature08355

Waples, D., \& Waples, J. (2004). A review and evaluation of specific heat capacities of rocks, minerals, and subsurface fluids. Part 1: Minerals and nonporous rocks. Natural Resources Research, 13(2), 97-122. https://doi.org/10.1023/B:NARR.0000032647.41046.e7

Watson, A. D., Moore, D. P., \& Stewart, T. W. (2004). Temperature influence on rock slope movements at Checkerboard Creek. In W. Lacerda, M. Ehrlich, S. A. B. Fontoura, \& A. S. F. Sayao (Eds.), Landslides: Evaluation and stabilization. Proceedings of the Ninth International Symposium on Landslides, edited by, (pp. 1293-1298). London: Taylor and Francis.

Wegmann, M. (1998). Frostdynamik in hochalpinen Felswänden - am Beispiel der Region Jungfraujoch-Aletsch, Ph.D. thesis, ETH, Zurich.

Wegmann, M., \& Gudmundsson, G. H. (1999). Thermally induced temporal strain variations in rock walls observed at subzero temperatures. In K. Hutter, Y. Wang, \& H. Beer (Eds.), Advances in cold-region thermal engineering and sciences, (pp. 511-518). Berlin Heidelberg: Springer. doi:https://doi.org/10.1007/BFb0104208

Wegmann, M., Gudmundsson, G. H., \& Haeberli, W. (1998). Permafrost changes in rock walls and the retreat of alpine glaciers: A thermal modelling approach. Permafrost and Periglacial Processes, 9(1), 23-33. https://doi.org/10.1002/(sici)1099-1530(199801/03)9:1<23::aidppp274>3.0.co;2-y

Wirsig, C., Zasadni, J., Christl, M., Akçar, N., \& Ivy-Ochs, S. (2016). Dating the onset of LGM ice surface lowering in the High Alps. Quaternary Science Reviews, 143, 37-50. https://doi.org/10.1016/j.quascirev.2016.05.001

Zhang, T. (2005). Influence of the seasonal snow cover on the ground thermal regime: An overview. Reviews of Geophysics, $43, \mathrm{RG} 4002$. https://doi.org/10.1029/2004rg000157 